University of Louisville

ThinkIR: The University of Louisville's Institutional Repository

Electronic Theses and Dissertations

$5-2012$

\title{
Adolescent steroid use : a logistic regression analysis.
}

Anthony Gennaro Vito 1987-

University of Louisville

Follow this and additional works at: https://ir.library.louisville.edu/etd

\section{Recommended Citation}

Vito, Anthony Gennaro 1987-, "Adolescent steroid use : a logistic regression analysis." (2012). Electronic Theses and Dissertations. Paper 1494.

https://doi.org/10.18297/etd/1494

This Master's Thesis is brought to you for free and open access by ThinkIR: The University of Louisville's Institutional Repository. It has been accepted for inclusion in Electronic Theses and Dissertations by an authorized administrator of ThinkIR: The University of Louisville's Institutional Repository. This title appears here courtesy of the author, who has retained all other copyrights. For more information, please contact thinkir@louisville.edu. 


\title{
ADOLESCENT STEROID USE: A LOGISTIC REGRESSION ANALYSIS
}

\section{By}

Anthony Gennaro Vito

B.S., University of Louisville, 2010

\begin{abstract}
A Thesis
Submitted to the Faculty of the

College of Arts and Science of the University of Louisville

In Partial Fulfillment of the Requirements

for the Degree of

Master of Science

Department of Justice Administration

University of Louisville

Louisville, Kentucky
\end{abstract}

May 2012 
Copyright 2012 by Anthony Gennaro Vito

All rights reserved 
Adolescent Steroid Use: A Logistic Regression Analysis

$$
\text { By }
$$

Anthony Gennaro Vito

B.S., University of Louisville, 2012

A Thesis Approved on

April 11, 2012

by the Following Thesis Committee

Dr.'George E. Higgins Théßis 'Director

Dr. Seana Golder




\section{DEDICATION}

This thesis is dedicated to my parents Dr. Gennaro F. Vito and Mrs. Mary J. Vito 


\section{ACKNOWLEDGMENTS}

I would like to thank Dr. George E. Higgins for his guidance and patience throughout this process. Dr. Higgins has provided me with great education and provided me with wonderful insight and knowledge into the research process. I would like to thank the other committee members, Dr. Geetha Suresh and Dr. Seana Golder, for their willingness to serve on my thesis committee. Finally, I would like to thank Dr. Aaron Striegel for starting my interests in drug research. 


\begin{abstract}
ADOLECENT STEROID USE: A LOGISTIC REGRESSION ANALYSIS Anthony Gennaro Vito

April 11, 2012

This study compared the criminological theories of peer association and low selfcontrol and its effect on adolescent steroid use. The data for this study comes from the $12^{\text {th }}$ grade survey of the 2009 Monitoring the Future Project Form 6 . The purpose of the Monitoring the Future Project (MTF) is to understand changes in values, behaviors, and lifestyle orientations of the American youth. The study found that peer association, low self-control and the sex of the adolescent are all significant predictors of adolescent
\end{abstract} steroid use. 
TABLE OF CONTENTS

PAGE

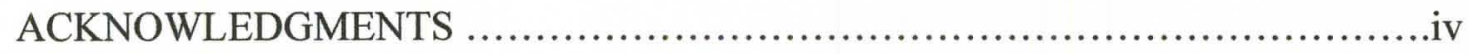

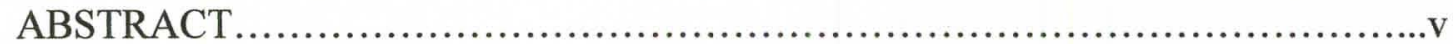

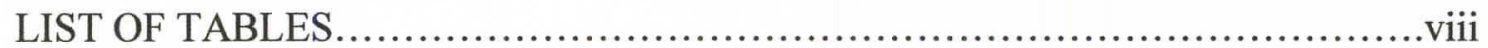

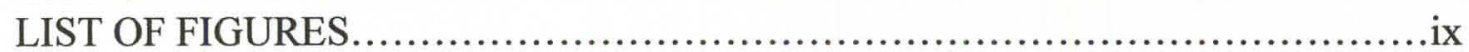

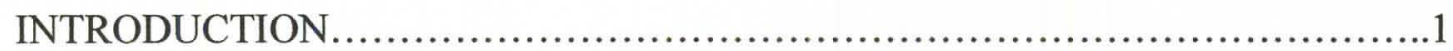

Adolescent Steroid Use.....................................................

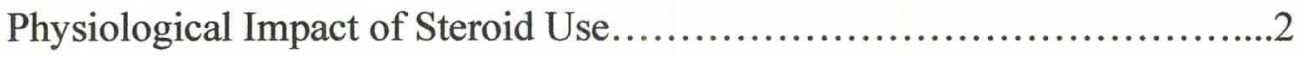

Physical Symptoms............................................

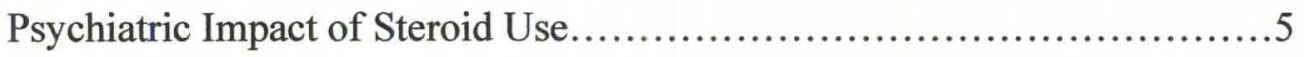

Evidence from Prospective Studies....................................5

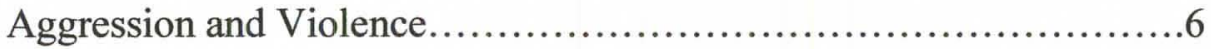

Predominant Mood Symptoms...................................... 9

Psychosis..........................................................

Depression and Withdrawal...................................... 11

Other Psychiatric Co-Morbidities..................................12

Comparing Males and Females........................................... 13

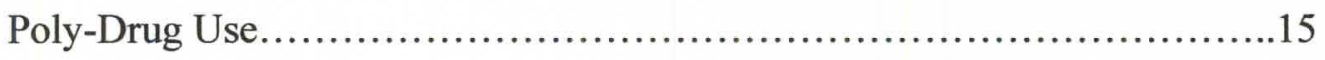

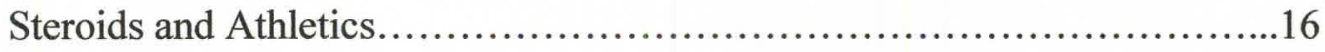


Steroids and Socio-Economic Status..................................20

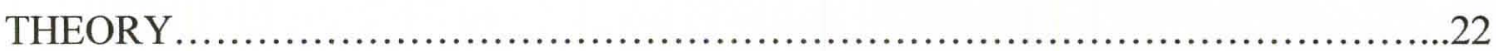

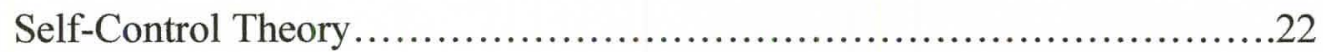

Literature Review on Self-Control Theory........................24

Peer Association.................................................. 31

Literature Review on Peer Association..............................32

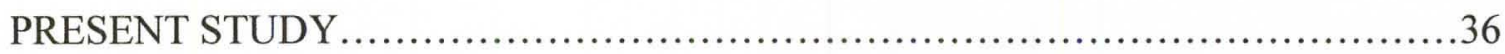

Methods.................................................................

Measures....................................................... 38

Dependent Measures..........................................38

Independent Measures...........................................39

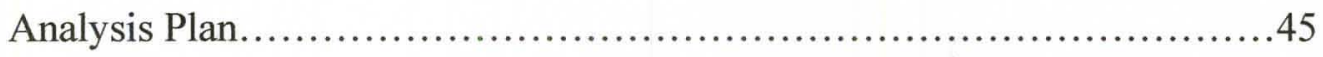

RESULTS......................................................................

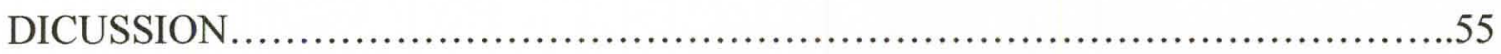

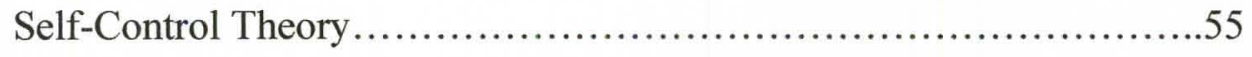

Differential Association..........................................56

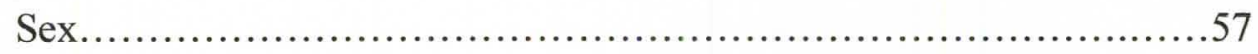

Policy.....................................................57

Limitations..............................................59

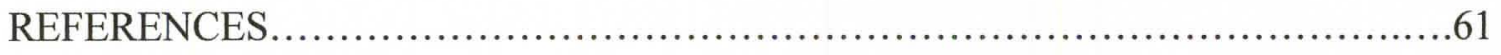

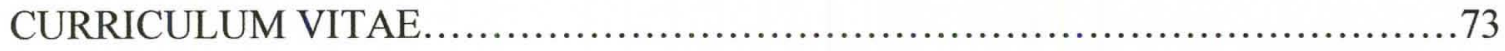




\section{LIST OF TABLES}

TABLE

PAGE

1. Total Variance Explained..............................................43

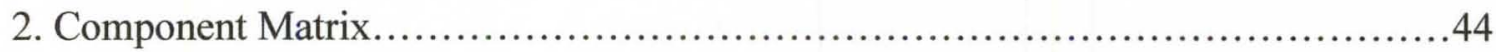

3. Reliability Statistics...................................................44

4. Descriptive Statistics................................................. 40

5. Logistic Regression Analysis: Lifetime Steroid Use............................41

6. Logistic Regression Analysis: Steroid Use in the Last 12 Months...................42

7. Logistic Regression Analysis: Steroid Use in the Last 30 Days...............................43 


\section{LIST OF FIGURES}

FIGURE

PAGE

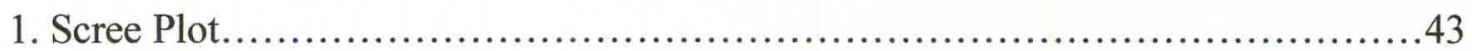




\section{CHAPTER I}

\section{INTRODUCTION}

\section{Adolescent Steroid Use}

Anabolic-androgenic steroids (AAS) are chemically created variants of the male sex hormone testosterone (National Institute on Drug Abuse, 2009). "Anabolic" means muscle-building, and "androgenic" means to increase male sexual characteristics (National Institute on Drug Abuse, 2009). "Steroids" represents the class of drugs (National Institute on Drug Abuse, 2009).

Adolescent steroid use has been estimated to start by the age of 16 for two thirds of adolescent steroid users (Congeni \& Miller, 2002). Steroid use at the middle school is that steroid use among seventh graders is approximately 2.5 percent (Congeni \& Miller, 2002). Recent studies show the extent of that problem (Potteiger \& Stilger, 1994; Terney \& McLain, 1990; Buckely et al., 1988; Johnson et al., 1989). For instance, in 1988, Potteiger and Stilger surveyed 190 high school football players in Texas, and 1 percent reported using steroids. Buckley et al. (1988) surveyed more than 3400 senior male athletes from 46 private and public high schools. They found 6.6 percent admitted to steroid use. Terney and McLain (1990) surveyed 2100 students and results showed 4.4 percent used steroids. In addition, of the 1435 students who said they were athletes, 5.5 percent admitted to steroid use (Terney \& McLain, 1990).

Radakovich, Broderick, and Pickell (1993) examined steroid use of seventh graders at a Modesto, California middle school and found that 4.7 percent of males and 
3.2 percent of females said they used steroids. In 1992-1993, a survey was conducted in10 Denver highs schools where researchers discovered overall use of steroids was 2. percent (Tanner, Miller, \& Alongi, 1995). The use of steroids by males was 4 percent and for females was 1.3 percent (Tanner et al., 1995). Stilger and Yesalis (1999) surveyed Indiana high school football players and found that 6.3 percent either had used or were using steroids. Miller (2009) estimated in 2003 that more than 1 million adolescents aged 12-17 had taken steroids and everyone surveyed knew someone who used steroids.

While steroids are becoming a problem for adolescents, the consequences of using steroids are dangerous to their health. The health problems they might encounter are both physical and psychological.

\section{Physiological Impact of Steroid Use}

Although adolescents see benefits of steroid such as an increase in muscle mass and strength, there are detrimental consequences which come with the use of steroids(Urdang, 2009). Steroid use can cause physical harm to the human body. The causes of such physical problems can be based on the amount of use, age of the user, and type of steroid. The physical problems are different for both males and females.

\section{Physical Symptoms}

The use of steroids can result in physical side effects. The most common side effects for males are: decreased testosterone production, decreased spermatogenesis, and testicular atrophy (Elliot \& Goldberg, 2000; American Academy of Pediatrics, 1997; Bagatell \& Bremner, 1996; Harlan, Grillo, Cornoni-Huntley \& Leaverton, 1979). Decreased testosterone production is a decrease in testosterone, the principal male sex 
hormone (Urdang, 2009). Spermatogenesis is the process of mature sperm being produced in the testes (Urdang, 2009). Testicular atrophy is the shrinking of the testicles (Urdang, 2009). These conditions adversely affect the quality of life for males.

The most common side effects for females are androgenization and clitoral hypertrophy (Elliot \& Goldberg, 2000; Franke \& Berendonk, 1997; American Academy of Pediatrics, 1997). Androgenization is the development of secondary male sexual characteristics in females such as excessive body hair and male-pattern baldness (Urdang, 2009). Clitoral hypertrophy is an increase in the size of the clitoris (Urdang, 2009).

An early indicator of steroid use is severe acne (for both sexes) and the development of gynaecomastia, which is defined as the enlargement of the breasts in males by either a hormone imbalance or hormone therapy (Urdang, 2009; American Academy of Pediatrics, 1997; Kirlay, 1988). Sudden cardiac arrest and myocardial infarction (MI), the death of a segment of heart muscle that interrupts the flow of blood supply also known as a "heart attack," have been linked to steroid use (Urdang, 2009; Huie, 1994; Ferenchick \& Adelman, 1992; Bowman, Tanna, Fernando, Ayodeji, \& Weatherstone, 1989; McNutt, Ferenchick, Kirlin, \& Hamlin, 1988). When looking at current steroid users and past steroid users, results show only current users to have left ventricular hypertrophy, increased interventricular septal thickness, and decreased maximum oxygen up take (Trenton \& Currier, 2005; Fisher, Appleby, Rittoo, \& Cotter, 1996; Nieminen, Raemoe, Viitasaio, Heikkilae, Karjalainen, Maentysaari, \& Heikkilae, 1996; (Dickerman, Schaller, Prather, \& McConathy, 1995; Luke, Farb, Virmani, \& Sample, 1990; Mochizuki \& Richter, 1988). Ventricular hypertrophy takes place particularly in the left ventricle and can cause enlargement of the heart that may restrict 
blood flow and cause the heart muscle to weaken due to overuse (Urdang, 2009). An increased interventricular septal thickness occurs when the two ventricles in the septal of the heart walls thicken, putting greater pressure on the heart to pump blood through the heart that can cause sudden cardiac arrest and myocardial infarction (Urdang, 2009).

Those who use steroids and power lifted have been shown to have an increased of risk of atherosclerosis secondary to increased levels of low-density lipo-protein (LDL) cholesterol and decreased levels of high-density lipoprotein (HDL) (Trenton \& Currier, 2005; Kennedy \& Lawrence, 1993; McNutt et al., 1988). Atherosclerosis is the development of fatty plaques on the inner walls of the arteries causing obstruction of blood flow (Urdang, 2009). The low-density, lipo-proteins help transport cholesterol in the bloodstream (Urdang, 2009). High-density, lipo-protein, on the other hand, help with the transportation of cholesterol from the tissues to the liver (Urdang, 2009).

Severe damage can be done to the liver particularly from oral steroids. Damage to liver can include hepatocellular damage and cholestasis, (American Academy of Pediatrics, 1997; Cabasso, 1994; Creagh, Rubin, \& Evans, 1988; Goldman, 1985; Overly, Dankoff, Wang, \& Singh, 1984). Hepatocellular damage is done to liver cells (Urdang, 2009). Cholestasis is a liver disease caused by failure of normal amounts of bile to reach the intestine (Urdang, 2009). Steroid users are at greater risk of infectious diseases because of non-sterile injection techniques and shared needles (Trenton \& Currier, 2005; Scott \& Scott Jr., 1989: Sklarek, Mantovani, Erens, Heisler, Niederman, \& Fein, 1984). Due to such unhealthy practices, steroid users have greater chance of getting viral infections such as HIV and hepatitis B and C (Trenton \& Currier, 2005; Scott \& Scott Jr., 1989; Sklarek et al.,1984) 


\section{Psychiatric Impact of Steroid Use}

Physical consequences are not the only effects of steroids. Steroids can also influence a person's psychological well-being. This can take place in the form of violence, aggression, mood swings, depression, and psychosis.

\section{Evidence from Prospective studies}

The use of anabolic steroids can cause mental status and behavioral changes such as irritability, aggressiveness, euphoria, depression, mood swings, altered libido, and psychosis (National Institute on Drug Abuse, 2009). Psychiatric dysfunction has been reported from preclinical, clinical, and anecdotal reports on steroid use. Steroids may have a negative impact on relationships and continued use of steroids can cause users to become addicted. In addition, users spend large sums of money and time getting the drug. Avary and Pope (2000) showed steroid users might turn to other drugs to ease the side effects. Of the 227 men in the study, 9.3 percent abused steroids before other drugs and 86 percent used opioids to offset insomnia and irritability (Avary \& Pope, 2000).

Pope, Kouri, and Hudson (2000) conducted a study on the effects of anabolicandrogenic steroids in males to see if it causes manic or aggressive reactions. The study consisted of 56 men with ages ranging from 20-50. Researchers gave the participants intramuscular testosterone treatment doses of $600 \mathrm{mg} /$ wk (Pope, Kouri, \& Hudson, 2000). All participants were randomized to either receive testosterone or a placebo for six weeks followed by washout period of six weeks and then opposite treatment for six weeks followed by another washout for six weeks. The washout period is where the participants cycled off from using either testosterone or the placebo. During the washout 
period, the participants did not receive any kind of treatment. Evidence from the study on the measure of Young Mania Rating System (YMRS) showed 42 men demonstrating minimal psychiatric effects, six being mildly hypomanic and two men being markedly hypomanic (Pope et al., 2000).

\section{Aggression and Violence}

One of the negative side effects of steroid use is that it promotes aggression and violence among users (Bjorkqvist, Nygren, Bjorklund, \& Bjorkqvist, 1994; Choi, Parrott, \& Cowan, 1990; Kouri, Lukas, Pope, \& Oliva, 1995; Thilbin, Kristiansson, \& Rajs, 1997; Yates, Perry, \& Murray; Yates, Perry, \& Murray, 1992). Parrott, Choi, and Davies (1994) studied 21 amateur athletes comparing steroid and non-using steroid psychological states during on-steroid periods. They found that athletes suffered from: elevated feelings of aggression, aggression toward objects, verbal aggression and aggression during training. Steroids can cause aggressive behavior in females. A study was conducted looking at the physiological and psychological effects of steroids on women. The study consisted of 75 female athletes and found that 25 were steroid users. Of those 25,13 reported being irritable and 10 reported behavior perceived as aggressive (Gruber \& Pope, 2000). Choi and Pope (1994) conducted a study comparing violence and verbal aggression towards women by 24 males who were using steroids close to the time of the act and 14 who have never done steroids. The findings showed steroid users were in more fights, reported being verbally and violently more aggressive toward their partner while taking steroids (Choi \& Pope, 1994). Trenton and Currier (2005) identified $(\mathrm{N}=164)$ as current steroid users, past steroid users or non-users, evidence showed 12.9 
percent of current users and 15.2 percent of past users showed psychological dependence of steroids.

A study was done on the relationship between steroid abuse and crime. In a study of 133 prisoners on steroid abuse in relation to crime, seven admitted to using large amounts of steroids (Trenton \& Currier, 2005). Of the seven admitted users, four stated they had no psychiatric change while three admitted to having obvious changes in mood and levels of irritability associated with steroid use. Of the three who admitted mood changes, one prisoner attributed steroids to his previous criminal activity. One prisoner admitted to have taken two cycles of steroids of 1000-1500 milligrams per week of testosterone several years earlier (Trenton \& Currier, 2005). The two other prisoners credit steroids with their incarceration, and one admitted using multiple steroids for six years and while the other prisoner was prescribed replacement testosterone and had used in greater amounts then the recommend dose (Trenton \& Currier, 2005).

Pope and Katz (1990) associated steroid use with violent crime in three cases of homicide or near homicide. All three subjects had used steroids in the previous two to four years and exhibited symptoms of severe irritability, grandiosity, paranoid suspicions, decreased sleep, explosive temper and reckless behavior (Pope \& Katz, 1990). Two of the users meet the requirements of DSM-III-R for experiencing a manic episode. All three, after they stopped using steroids behavior, returned to their normal personality (Pope \& Katz, 1990).

Lundholm et al. (2010) also found a correlation between violent crime and steroid use. They looked at the effect of taking steroids in relation to committing violent crimes in Sweden prison population from 2002-2008. The study found those who used steroids 
were more likely to have been arrested for suspected violent crime (Lundholm, Kall, Wallin, \& Thiblin, 2010). Of the total prison population (3597) arrested, 924 admitted to the use of steroids, 36 percent or 335 prisoners had committed a violent crime. However, there was no correlation between the amount of steroid used and the number of violent crimes committed (Lundholm et al., 2010). Lundholm et al. (2010) may not have studied adolescents, but there data could also provide some support to violence and steroid use within the teenage population. There are two factors that could attribute for the violent behavior. First, the use of steroids may be overrepresented in individuals who display risk-taking behavior (Lundholm et al., 2010). Second the long-term use of steroids could lower an individuals propensity to avoid violent behavior or cause triggers of violence, like alcohol does (Lundholm et al., 2010).

The use of steroids has been associated with violent crime in rare but extreme case. One steroid user was using steroids for three months when he committed murder (Trenton \& Currier, 2005). Another individual committed violent and aggressive acts such as breaking into a school, three incidents of assault and battery, attempted murder on one occasion and committed murder on another occasion (Trenton \& Currier, 2005). It was found that this individual had been using steroids over a span of two years starting at the age of 14 and had gone on nine cycles lasting between one and four weeks (Trenton \& Currier, 2005). Steroids have been linked to domestic violence. A study found that in a sample of 24 males with 10 identified as nonusers and 14 identified as users that the steroid users experience more fights, verbal aggression and violence towards their domestic partner (Trenton \& Currier, 2005). Suicide has been linked with steroid abuse. 
In a study of 11 male users, aged 21-39, it was found that six were using steroids when they committed suicide (Trenton \& Currier, 2005).

An analysis was done on the National Longitudinal Study of Adolescent Health from 1994-2002 looking at the effect of lifetime anabolic-androgenic steroids use on violent behavior among adult males. The study found males who admitted past using steroids at least once had higher rates of violent behavior in comparison to non-steroid users (Beaver, Vaughn, DeLisi, \& Wright, 2008). Males using steroids in the past year showed drastically higher rates of violent behavior compared to non-steroid users (Beaver et al., 2008).

Although violent crime cases linked with steroid use is rare, it is important to highlight this fact because it shows the dangers of steroid use. Some of the criminal activity includes homicides. In addition the amount of steroids used has shown to be a causal link to criminal activity and violence. Steroids has been shown to cause aggressive behavior in males and females.

\section{Predominant Mood Symptoms}

In a study of 160 athletes on the effects of anabolic androgenic steroid use, 88 athletes admitted using steroids. When taking steroids, there were four manic episodes reported, 11 reported suffering major depression and nine had a hypomanic episode (Pope \& Katz, 1994). Pope and Katz (1998) conducted a study on 39 steroid users and affective symptoms, 13 experienced manic symptoms with five meeting the criteria of DSM-III for a manic episode and eight barely failing to meet the criteria (Pope \& Katz, 1998). In a study done on the effects of steroids on 25 female bodybuilders, aged 18 - 65 , 
it was found that 14 had experience hypomanic symptoms while taking steroids (Trenton \& Currier, 2005).

Thiblin, Runeson and Rajs (1999) evaluated eight, suicide cases. The study found that long-term, steroid use causes an increase in the chance of suicide and showed impulsive behavior due to depression and lack of self-control (Thiblin et al., 1999). Cooper, Noakes, Dunne, Lambert and Rochford (1996) assessed the personality profiles of 12 steroid users and 12 non-steroid users over an 18-month period. The study found steroid users to have higher scores on measures of paranoid, schizoid, antisocial, borderline, histrionic, narcissistic and passive-aggressive personality traits (Cooper et al., 1996). The amount of steroids taken has been shown to cause manic episodes. The use of multiple steroids at one time can exacerbate manic occurrences. Most manic incidents take place during the withdrawal period from steroid use.

\section{Psychosis}

Psychosis is a group of mental disorders where the patient loses touch with reality (Urdang, 2009). A study of 41 bodybuilders and football players reported that five met the criteria of DSM-III-R for psychotic symptoms during use of steroids (Trenton \& Currier, 2005). Four subjects reported psychotic symptoms such as paranoia and referential thinking during steroid use (Trenton \& Currier, 2005). Pope and Katz (1987) reported two extreme cases of psychosis. The first was a man, who reported after two weeks of steroid use, sufferings from symptoms of depression combined with delusions of reference and visual auditory hallucinations (Pope \& Katz, 1987). The second case was of a 22 year-old male bodybuilder. After a taking a two eight-week cycle of steroids, he reported having paranoid delusions (Pope \& Katz, 1987). 


\section{Depression and Withdrawal}

A mental state, described as excessive sadness, is known as depression.

Withdrawal is the specific physical symptoms such as sweating, vomiting or tremors that are caused by withdrawal from the drug (Urdang, 2009). In a study of 164 subjects who were identified as current steroid users, past steroid users or non-users the evidence showed that 12.9 percent of current users and 15.2 percent of past users showed psychological dependence of steroids (Trenton \& Currier, 2005). A study of 45 weightlifters that use steroids displayed the following symptoms: withdrawal symptoms (84\%), more substance taken than intended (51\%), large amount of time expended on substance-related activity (40\%) and continued steroid use despite problems caused or worsened by use (37\%) (Trenton \& Currier, 2005).

Steroid dependence is described as being a biphasic model consisting of hyper adrenergic state followed by depression and craving for steroids. The hyper adrenergic state starts 1-2 days after the user's stops taking steroids and will last around 1 week. The second stage of depression and craving for steroids is what has been most reported in studies looking at dependence and withdrawal. The symptoms that most commonly happen are: fatigue, muscle and joint pain, decreased libido, insomnia, anorexia, dissatisfaction with body image, desire to take more steroids, headaches and depression (Trenton \& Currier, 2005). Psychological dependency has been shown in steroid users during the withdrawal phase. A number of steroid users exhibits symptoms of depression due to steroid dependency. Such symptoms of depression can include: fatigue, decreased libido, and anorexia. 


\section{Other Psychiatric Co-Morbidities}

Psychiatric co-morbidities are other psychiatric disorders that happen simultaneously with another unrelated disease or condition (Urdang, 2009). Porcerelli and Sandler (1995) conducted a study on 36 weightlifters. Sixteen had used steroids, and 20 had never used steroids. The study looked at the prevalence of narcissistic personality traits among steroid-abusing weightlifters. The study showed steroid users had considerably higher scores on dimensions of pathological narcissism and drastically lower scores on clinical ratings of empathy (Porcerelli \& Sandler, 1995).

Recent studies have shown a link between steroid abuse and opioid abuse. In a study of 227 men admitted to an inpatient substance abuse treatment facility for opioid abuse, 21 reported having a history of steroid abuse (Trenton \& Currier, 2005). It was found that 18 used opioids to offset withdrawal symptoms, specifically depression (Trenton \& Currier, 2005). In another study of 223 male substance abusers admitted into impatient substance abuse treatment program, researchers found 88 admitted to opioid abuse and 22 of the 88 also admitted to substance abuse problems with steroids (Trenton \& Currier, 2005). This study shows a correlation between steroid abuse and opioid abuse. Psychiatric co-morbidities have been found in steroid users. Some of the effects are pathological narcissism, lower levels of empathy and reverse anorexia (Porcerelli \& Sandler, 1995). Steroid abuse has been linked to use and abuse of opioids (Trento \& Currier, 2005).

\section{Comparing Males with Females}

The social problem presented by steroid use is not just limited to one sex. Although the research shows males are more likely to use steroids than females, the 
volume of each sex varies over time. Both teenage girls and boys believe steroids will give them advantages such as greater strength and chance at athletic success. They both turn to steroids for these benefits. The 1991 Centers for Disease Control and Prevention Youth Risk Behavior Survey found the rate of use for each sex to be different with males use at 4.08 percent and female use at 1.2 percent (Durant, Escobedo, \& Heath, 1995; Yesalis et al., 1997).

Research has shown a rise in male steroid use. Yesalis, Barsukiewicz, Kopstein, and Bahrke (1997) analyzed the YRBSS national survey for 1991, 1993 and 1995. The survey asks students from eighth through twelfth grade if they ever used steroids in their lifetime. Results showed a slight increase an adolescent male steroid use going from 2.7 percent to 3.7 percent (Yesalis et al., 1997). In another survey, the National Household Survey on Drug Abuse conducted from 1991 to 1994, the use of steroids for senior males was highest in 1994 at 3.8 percent and lowest in 1996 at 1.9 percent (Yesalis et al., 1997). Congeni and Miller (2002), in a multiple national studies, estimated the steroid use of U.S., high school students to range from 4 to 11 percent. Males are estimated to be two to three times more likely to use steroids compared to use other illegal drugs (Congeni \& Miller, 2002). The same increase of steroid use can be seen with females too. In the same YRBSS national survey, conducted in 1991, 1993, and 1995, researchers found an increase in steroid use from 0.8 percent in 1991 to 1.4 percent in 1996 (Yesalis et al., 1997). The National Household Survey on Drug Abuse also showed an increase from .2 percent in 1991 to .6 percent in 1994 (Yesalis et al., 1997).

Wichstrom and Pedersen (2001) compared male and female adolescent steroid use. The results of their study came up with predictors of being offered steroids. The 
study found the opportunity to be offered steroids rested on the following predictors: gender (male), having had sexual intercourse, having been offered marijuana, eating disorder, conduct problems of both overt destructive type and overt nondestructive type, and involvement in power sports (Wichstrom \& Pedersen, 2001).

Although female, steroid use is on the rise, girls use steroids at a much lower rate than males. Congeni and Miller (2002) estimated the use steroid use of females, from U.S. high schools, to be at 2.5 percent. A follow up study conducted by Miller et al, (2005) on 16,262 adolescents found 2 percent of females and 4.1 percent of males in the sample reported ever having used anabolic steroids without a doctor's prescription. A 2010 Monitoring the Future study on adolescent drug abuse also showed differences in the rates of steroid use among the sexes (Johnston, O'Malley, Bachman, \& Schulenberg, 2011). For adolescent males, researchers discovered rates of steroid use was 0.4 percent for eighth graders, 1.0 percent for sophomores, 1.7 percent for seniors (Johnston et al., 2011). For the adolescent females the rates of steroid use was 0.1 percent for eighth graders, 0.2 percent for sophomores, and 0.3 percent for seniors (Johnston et al., 2011).

Male and Female adolescent steroid use has been shown to increase by age. Males have been shown to use steroids at a greater rate than females. The greatest predictors of steroid use are: gender (male), having had sexual intercourse, and having been offered marijuana.

$$
\text { Poly-Drug Use }
$$

When teenagers use steroids, they may have a higher use of doing other drugs as well. Durant et al. (1995) showed evidence of a correlation between frequency of steroid use and other drugs. This researched showed 23 percent of the steroid users reported the 
use of cocaine, 14 percent used alcohol, and 12 percent used marijuana (Durant, Escobedo \& Heath, 1995).

Durant, Vaughn, Ashworth, Newman and Slavens (1993) examined the use of multiple drugs among adolescents who use anabolic steroids. In a survey of 1881 high school students, 4.2 percent reported use of anabolic steroids with 6.1 percent being males and 1.9 percent being females (Durant et al., 1993). It was found that among steroid users, 24.7 percent shared needles to inject drugs within the past 30 days (Durant et al., 1993). Correlations were found between steroid use and the following drugs: cocaine, marijuana, shared-needle, and smokeless tobacco (Durant et al., 1993).

Denham (2009) found the strongest correlations of adolescent who use steroids also use GHB (ie., central nervous system depressant, used as a club drug for its intoxicating effects) and Rohypnol (ie., a sedative causes muscle relaxation and amnesia, used as a "date rape" drug). Alcohol consumers were also more likely to use steroids (Denham, 2009). The use of narcotics showed to have impact on the likelihood of using steroids (Denham, 2009). The 2009 National Youth Risk Behavior Survey (YRBSS) showed that 3.3 percent of students had taken steroid pills or shots without a doctor's prescription at least once during their lifetime (Youth Risk Behavior Survey, 2009). A study of steroid use from the 1991 National Household Survey on Drug Abuse showed those who reported the use of steroids are three to four times more likely to be users of alcohol and cigarettes (Yesalis, Kennedy, Kopstein, \& Bahrke, 1993).

Research shows a link between steroid use and using other drugs. Some of other drugs being used are: cocaine, alcohol, and GHB. Adolescents who consume alcohol are at greater likelihood to also use steroids. 
Steroids and Athletics

Athletes in general or adolescent also have a greater use of steroids, especially those who take part in strength-dependent sports such as football and wrestling (Congeni \& Miller, 2002). The earliest reported use of steroids in high school occurred in 1959 when a physician supposedly distributed Dianabol to a high school football team (Yesalis, Courson \& Wright, 2000).

The reason these athletes use steroids could also explain why Wichstrom and Pedersen (2001) found more athletes use steroids when they are involved in competitive sports. A 2000 study, which explored the use of steroid use among Norway teenagers, found evidence showing the higher level of sport competition the greater the likelihood of steroid use (community level .5 percent vs. international level 2.5 percent), and there was also more opportunity (Wichstrom \& Pedersen, 2001). Those involved in competition sports had a higher chance of being offered steroids (Wichstrom \& Pedersen, 2001). Johnson, Jay, Shroup and Rickert (1989) conducted a survey on steroid use on 853 male students in six Arkansas high schools, discovering that 84 percent of the admitted 95 steroid users had participated in competitive or non-competitive sports (Johnson et al., 1989). They found 95 students who reported past or present use of steroids (Johnson et al., 1989). The researchers asked the boys about why they used steroids. Sixty-four percent wanted to increase strength, 50 percent wanted to increase size, 27 percent wanted to improve their physical appearance, and 10 percent used steroids because their friends were using them (Johnson et al., 1989).

Steroids have another effect on athletes too. A 2002 study found steroid users exhibited behavior usually found in the opposite gender (Miller, Barnes, Sabo, Melnick, 
\&Farrell, 2002). When looking at high school athletes, steroid users have a greater likelihood of engaging in problem behaviors than nonusers (Miller et al., 2002). In addition, Miller et al (2002) discovered that gender-atypical activities (such as aggression for females, or pathogenic weight loss for males) were increased for those using steroids compared to nonusers. For this reason, a comparison of male and female athletes showed steroid use was linked with a greater chance of participation in gender-atypical health risk activities (Miller et al, 2002).

The first reported problem with steroids in the Olympics happened in 1964 specifically in strength sports (Yesalis et al., 2000). According to Dr. Tom Waddell, by 1968 he estimated that one-third of the entire U.S. track-and-field team had taken steroids (Todd, 1987). By the 1990s the use of steroids in the Olympics had spread from weightlifting and track and field event to other sports such as hockey, swimming and soccer (Yesalis et al., 2000).

The use of steroids by female athletes was first noticed in the 1968 Olympics. Those females were throwers from Eastern European Communist bloc countries (Franke \& Berendonk, 1997). Starting in the late 1970s female steroid use had spread to other sports such as swimming and rowing (Franke \& Berendonk, 1997). In 1995 the youngest reported use of steroids by a female came from a 14-year old female long jumper and sprinter ( Yesalis et al., 2000).

Steroid use was not just used by Olympians. It was also used in professional football. The first reported use took place in 1963 involving the San Diego Chargers (Yesalis et al., 2000). By the end of the 1960s, steroid use had spread to the Kansas City Chiefs, Atlanta Falcons, and the Cleveland Browns (Yesalis et al., 2000). Former NFL 
player Pat Donovan of the Dallas Cowboys, who played from 1974-1983, claimed that 60 to 70 percent of the Cowboys on the offense and defensive lines used steroids (Johnson W., 1985). Fred Smerlas, who played for the Buffalo Bills, estimated that steroid use throughout the entire league was 40 percent (Johnson W., 1985). Some other NFL players have made claims that steroid was as high as 90 percent (Johnson W., 1985).

The use of steroids has been claimed to be seen in the physical size of NFL players. In 1987 there were only 20 players who weighed more than 300 pounds (Noonan, 1997). Yet, by 1997 there were 240 players who weighed more than 300 pounds. (Noonan, 1997). Researchers have debated for a reason for the size increase. Some argue that it is related to high-calorie diets and food supplements while others said it was steroids and human growtha hormone (Noonan, 1997; Bamberger \& Yaeger, 1997).

Steroids also infiltrated college football. By the 1980s steroid use was rampant across the country at such universities as Stanford, University of Oklahoma, University of Southern California and University of Texas (Yesalis et al., 2000). Nebraska and Notre Dame have been associated in widespread steroid use (Yesalis et al., 2000). Estimations claim that as high as $85 \%$ of the Nebraska football team used steroids between $1983-1984$ (Keteyian, 1987). Anderson, Albrecht, McKeag, Hough and McGrew (1991) conducted an anayomons survey of Division I-III college athletes. The results of this study show that on average $10 \%$ of college football players have used steroids in the past year (Anderson et al., 1991).

Steroid use has also taken place in Major League Baseball. Randy Smith former general manager of the San Diego Padres claims that $10-20 \%$ of players use steroids 
(Nightengale, 1995). An anyomous American League general manger has stated he would not be surprised if the use of steroids was closer to $30 \%$ (Nightengale, 1995).

In athletics the use of steroids is widespread no matter the type of sport (Johnson W., 1985; Keteyian, 1987; Todd, 1987; Anderson et al., 1991; Nightengale, 1995; Bamberger \& Yaeger, 1997; Noonan, 1997; Yesalis et al., 2000). The use of steroids can first be seen in the Olympics. However, it spread to other professional sports such as the NFL and MLB. The greatest use of steroids can been seen in college and professional football. Professional and collegiate atheltics can dramatically changes one's personal socio-economic status. Some atheletes may use steroids to achieve this goal.

Steroids and Socio-Economic Status

Humphreys and Ruseski (2011) use the YRBSS data to look at socio-economic status to explain high school athlete's use of steroids. They discovered some athletes use steroids to get those sought-after college scholarships. For instance, the 2011 study shows multi-sport athletes are more likely to use than those who only play one sport (Humphreys \& Ruseski, 2011). According to the researchers, multi-sport athletes use steroids to improve chances of obtaining a scholarship since they already have a greater opportunity at obtaining such a reward due to their wide range of athletic skills.

Humphreys and Ruseski (2011) also discover a connection between upper class rank student athletes using steroids more than under class rank. They say as students advance through high school, participation in sports decreases. The athletes who are still playing are the best athletes. Their chances at an athletic scholarship are even greater than the underclassmen. Thus, they hope steroids will give them an even better chance (Humphreys \& Ruseski, 2011). These financial factors can also be seen when comparing 
genders. More males, who are multi-sport athletes, use steroids because good, athletic performance is associated with lucrative careers in professional and collegiate sports (Humphreys \& Ruseski, 2011). In comparison female athletes are more likely to use steroids when wanting to increase their weight (Humphreys \& Ruseski, 2011).

Athletes may use steroids as a way to obtain a college scholarship. Multi-sport athletes are at greater risk to use steroids then one-sport athletes, because athletes who play more than one sport have more opportunity for scholarships. Male athletes use steroids as a way to enhance athletic performance that may lead to lucrative professional careers while female athletes use steroids primarily to gain weight. All of the information on adolescent steroid use provides context but not a theoretical explanation of the use. The information offered is correlates. 


\section{CHAPTER II}

Theory

The previous sections described the use and harmful consequences of adolescent steroid use, and the differences and similarities among correlates. The results shown provide context but no explanation, because they fail to explain the criminological reasons why one would use steroids. Previous research has sought to explain why adolescents' use steroids by looking at gender, athletics, physical appearance and psychological factors (Johnson et al., 2011; Trenton \& Courier, 2005; Congeni \& Miller, 2002). Yet, steroid use is a crime similar to other illegal drug use such as marijuana and cocaine (Durant et al., 1995). For this reason, criminological theories should be used to explain why adolescents use steroids.

Theory is a set of interconnected statements or propositions that explain how two or more events or factors are related to one another (Akers \& Sellers, 2009). When a theory is developed properly it can explain real situations, feelings, experience and human behavior (Akers \& Sellers, 2009). Theories help rationally explain empirical data and help in understanding why certain behaviors occur (Higgins, 2005). In the absence of theory, significant variables are only correlates. Theory helps explain why people perform behaviors in this study of adolescent steroid use.

\section{Self-Control Theory}

One of the most popular criminological theories that may help in understanding adolescent steroid use is Gottfredson and Hrschi's (1990) General Theory of Crime. 
Gottfredson and Hirschi's (1990) theory makes the assumption that individuals are rational decision makers. This means that an individual makes a calculated decision by weighing the benefits of the outcome against the consequences. This theory assumes people seek pleasure (benefits) and avoid pain (consequences).

Gottfredson and Hirschi (1990) define crime as an illegal act typically in the form of force or fraud. Six characteristics make up crime. The first is that criminal acts provide immediate gratification of desires; it is the concept of "here and now" (Gottfredson \& Hirschi, 1990). The second is that the criminal act is an easy way to provide gratification of desires (Gottfredson \& Hirschi, 1990). Features of this characteristic include an individual with low self-control who lacks diligence, tenacity or persistence (Gottfredson \& Hirschi, 1990). Third, is that the criminal act is exciting, risky or thrilling (Gottfredson \& Hirschi, 1990). Traits of this characteristic include being adventuresome, active, and physical (Gottfredson \& Hirschi, 1990). Fourth, is that the crime provides few if any long-term benefits (Gottfreson \& Hirschi, 1990). Individuals with this characteristic have no desire in and are unprepared for long-term occupational goals (Gottfredson \& Hirschi, 1990). Fifth, is that to commit a crime requires little skill or planning (Gottfredson \& Hirschi, 1990). Individuals with low selfcontrol do not have or place importance on cognitive or academic skills (Gottfredson \& Hirschi, 1990). Sixth, is criminal activity often results in pain or discomfort for the victim (Gottfredson \& Hirschi, 1990). Features of this characteristic are that an individual with low self-control can be self-centered and do not care about the suffering and needs of others (Gottfredson \& Hirschi, 1990). 
According to Gottfredson and Hirschi (1990), individuals with low self-control cannot withstand the lure of pleasure because they cannot see the long-term consequences. These individuals display such characteristics that can affect one's ability to gauge the consequences of their actions; thus, they will see the pleasure and not the pain of their decision. Such individuals who have low self-control share common characteristics: impulsiveness and insensitivity, an attraction to easy and simple tasks, risks, and physical activities (Gottfredson \& Hirschi,1990; Higgins \& Mahoney, 2010).

Children with low self-control are the byproduct of households with poor or ineffective parental management (Gottfredson \& Hirschi, 1990; Higgins \& Mahoney, 2010). Parents need to establish a strong emotional bond to better monitor their child's behavior (Gottfredson \& Hirschi, 1990). Such parents are able to discipline their child when the child displays deviant behavior. The absence of effective parental management can create an environment that may cause the child to develop low self-control (Gottfredson \& Hirschi, 1990).

According to Gottfredson and Hirschi (1990) self-control levels explains the propensity for criminal activity. Parents must create a strong emotional bond with the child and monitor the child's behavior to stop the child from developing low self-control.

\section{Literature Review on Self-Control Theory}

Previous studies have used low-self control to explain crime. Pratt and Cullen (2000) conducted a meta-analysis on the empirical status of Gottfredson and Hirschi's general theory. The overall findings, from Pratt and Cullen (2000), showed self-control was a strong predictor of crime and analogous behavior with a mean effect size above .20. The study also found that social learning variables (i.e., peer association) still have a 
strong effect as a predictor of crime. Pratt and Cullen (2000) study shows that selfcontrol does help in explain criminal and analogous behavior, yet it is not the general theory of crime predictor that Gottfredson and Hirschi claim it is there is still empirical support for social learning theory.

Sorenson and Brownfield (1993) conducted a study using the Seattle Youth Study of 1981, asking male and female high school students about drug use. The students were asked if they ever used alcohol, marijuana, barbiturates, LSD, or cocaine. The study found that all measures of self-control are significantly correlated to adolescent drug use (Sorenson \& Brownfield, 1995). Consistent with Gottfredson and Hirschi (1990), the study found perceived risk of punishment and parental supervision to be significant predictors of drug use (Sorenson \& Brownfield, 1995). Those youth, who used drugs, were not afraid of punishment and had low, parental supervision (Sorenson \& Brownfield, 1995). The study also found peer delinquency and attachment to peers was positively correlated with drug use (Sorenson \& Brownfield, 1995).

In another study, Ragan and Beaver (2010) researched the life-course of marijuana users, starting in 1994, using the National Longitudinal Study of Adolescent Health (Add Health). The study interviewed 90,000 students who were attending 132 middle and high schools. A subsample was created that used 20,745 adolescents. The survey was conducted in three waves. Researchers asked students if they had used marijuana in the last 30 days. Low self-control was identified at wave 1 with marijuana use if the adolescent had any of the following problems: (1) difficulty getting along with teachers, (2) trouble paying attention in school, (3) difficulty concentrating and (4) trouble finishing homework (Ragan \& Beaver, 2010). Ragan and Beaver (2010) found, 
at wave 1 and wave 2, that associating with delinquent peers was predictive of marijuana use, membership into the "chronic users" group, and trying marijuana before the age of 15. The study found that stopping association with delinquent peers seven years later was a predictor of desistance from marijuana (Ragan \& Baker, 2010). Marital status was found to be a predictor of desistance from marijuana use (Ragan \& Baker, 2010). The interviews at wave 3 identified low self-control with marijuana use if the participants did any of the following things: (1) how often they try new things for fun, (2) do things based on how they feel at that moment and (3) act on their instincts without thinking things through (Ragan \& Beaver, 2010). In phase three, it is easy to see, based on the participants' actions, their need for pleasure.

Sun and Longazel (2008) conducted a study to see how binge drinking, drinkingdriving and other negative alcohol-related behaviors can be explained by low self-control. Sun and Longazel (2008) interviewed 558 undergraduate students for this study. The social bonds of commitment and involvement such as attending events or activities put on by the university were found to be a strong predictor of desistance from alcohol. (Sun \& Longazel, 2008) A weak link was found with those involved in athletics, fraternities, or sororities. These members were more likely to participate in binge drinking (Sun \& Longazel, 2008). In terms of routine activities, participating in unsupervised activities such as frequent partying resulted in users binge drinking (Sun \& Longazel, 2008). Low self-control was the strongest predictor for both drinking-driving and other negative alcohol behavior (Sun \& Longazel, 2008). Looking at binge-drinking, low self-control explained 25 percent of the variance (Sun \& Longazel, 2008). 
Baker (2010) conducted a study on the effects of social attachments to adults on self-control with the issue of problematic drinking among adolescents. The study came from the second wave of the National Longitudinal Study of Adolescent Health (Add Health) consisting of 11,415 adolescents in the eighth through twelfth grades. Baker (2010) found problematic drinking was correlated with age, and desistance from problematic drinking was connected to religious activities and investment in conformity. The strongest correlation in the study was the effect associating with delinquent peers has on problematic drinking (.555) (Baker, 2010). The study showed positive correlations between low self-control and the issue of problematic drinking (.268) (Baker, 2010).

Higgins, Mahoney and Ricketts (2009) examined the linkage between nonmedical use of prescripition drugs and social learning and self-control theories. The study was done using the 2006 Monitoring the Future (MTF) survey Form 2 that consisted of 2,458 students majority of who were over 18 . Peer associationg was found to be the strongest predictor of amphetamine use (Higgins et al., 2009). Low self-control explained, irregardless of other factors, the nonmedical use of sedatives and tranquilizers (Higgins et al., 2009). Individuals with high self-control were found to desist from all drug use at higher rates (Higgins et al., 2009).

De Li (2005) examined the issue of race as it relates to self -control and drug problems. His sample was made up of 500 jail inmates around the Philadelphia area. The results of the study showed that besides age, low self-control is most strongly associated with drug problems regardless of race ( $\mathrm{De} \mathrm{Li}, 2005)$.

A study done on Native American substance use compared how low self-control and native traditionalism explain substance use (Morris, Wood \& Dunaway, 2006). The 
study was conducted using a sample of 1,500 Oklahoma public high school students identified as Whites and Native Americans. The social bond attachment was found to increase Native American adolescents drug use if they felt an attachment with native traditions (Morris et al., 2006). Morris et al. (2006) found that low self-control is the best predictor of substance use when also using racial and cultural variability.

Longshore (1998) conducted a study on the effectiveness of self-control in comparison to criminal opportunity in explaining criminal behavior. The results showed that an offender with low self-control and reporting to have more criminal opportunity committed more property and personal crimes (Longshore, 1998). The findings show that self-control is a significant factor in explaining criminal behavior but is not dependent on criminal opportunity for criminal acts to be committed.

Longshore, Chang, Hsieh and Messina (2004) conducted a study on low selfcontrol in comparison to social bonds (attachment, involvement, religious commitment and moral belief) in explaining drug use in adult male drug offenders. The study found that low self-control was a strongly related to all four social bonds. Offenders with low self-control were found to have higher rates of drug use (Longshore et al., 2004). Those who were identified as having low self-control were found to have a greater proportion of friends who used drugs (Longshore et al., 2004). The only bond that was significantly correlated to drug use was moral belief (Longshore et al., 2004). The results of this study on the relationship between low self-control and drug show that 19 percent of the variance is explained by substance-using peer association and moral belief (Longshore et al., 2004). 
A study was conducted examining six individual differences that make up low self-control and how each one affects violent and property crimes and drug use among adolescent male offenders (Conner, Stein \& Longshore 2009). Those six differences include: impulsiveness, preference for physical activities, risk seeking, self-centeredness, preference for simple tasks and having a violent temper (Conner et al., 2009). Conner et al., (2009) found risk seeking to be significant at predicting both violent and property crimes but not drug use. The study found having a volatile temper helps in predicting violent crime and drug use but not property crime (Conner et al., 2009). The results of this study shows low self-control cannot explain for all criminal behavior as a single all encompassing concept.

Evans, Cullen, Burton, Dunaway, and Benson (1997) conducted a study on the effectiveness of self-control theory as a predictor of crime in comparison to social bonds, social learning, life-style, socioeconomic attainment and neighborhood context. The study found that by controlling for age and sex, low self-control is associated with crime and analogous behavior and a strong association between analogous behaviors and criminal involvement (Evans et al., 1997). When controlling for social factors, the measures of self-control remain a significant predictor of criminal behavior (Evans et al., 1997). Minimal effect was found for social bond measures as a predictor of criminal behavior (Evans et al., 1997). The social learning variables of criminal associates and internalized criminal values have similar effect size in comparison to self-control measures (Evans et al., 1997). This means that self-control is not the only significant predictor of criminal behavior (Evans et al., 1997). The results of this study show that 
self-control and social learning theories should not been seen as competing theories but as related theories in understanding criminal behavior.

Unhappy with the development self-control theory, Hirschi (2004) redefined selfcontrol. Hirschi's (2004) redefinition of self-control focuses on higher levels of selfcontrol. In this view self-control is a set of beliefs one carries with them everywhere that they go (Hirschi, 2004). These beliefs serve as consequences that the individual carries with them. Criminal acts then take place because of the lack of beliefs one holds in avoiding such actions. An individual will not commit a criminal act then due to the beliefs of the individual and the social bonds (i.e., commitment, involvement, belief, and attachment) that create the opportunity for disgrace if a wrongdoing is committed.

Adolescents who use steroids are suffering from low self-control. The adolescent wants the immediate gratification of enhanced performance without working for it. They are seeking pleasure (i.e., enhanced performance, improved physical appearance) and do not think about the consequences (i.e., physiological and psychological).

Empirical support has been found to support this theory in explaining criminal behavior. Piquero and Bouffard (2007) used data from college students to examine the reconceptualization of self-control to understand drunk driving and sexual aggression. Their study used three measures: a social bonding scale, Grasmick et al. (1993) scale, and a set of self-generated inhibitors. The self-generated inhibitors and the social bonding scale had stronger links than the Grasmick et al. (1993) scale with drunk driving and sexual aggression.

Higgins, Wolfe, and Marcum (2008) used college students to examine the link between similar measures as Piquero and Bouffard (2007) to understand digital piracy. 
Higgins et al. (2008) showed the social bonds can reduce the likelihood of digital piracy. Even with the revision, no research linking low self-control with adolescent steroid use is present in the literature. However, no studies have helped in explaing adolescent steroid use.

\section{Peer Association}

Differential association theory is another way of understanding adolescent steroid use. Edwin Sutherland (1947) explained criminal behavior as conduct that is learned in the same way as other behavior is learned (i.e., talking, walking, steroid use.). The process of learning of such behavior comes through differential associations such as intimate personal groups. Those within an intimate personal group either approve or disapprove of criminal behavior. Adolescents learn that the use of steroids is good or bad by the learned "definitions" (rationalizations and attitudes) of the group (Akers \& Sellers, 2009). This is what Sutherland calls the "principle of differential association (Akers \& Sellers, 2009)." The learning process involves acquiring the mechanical techniques (i.e., how to purchase steroids) of the behavior, yet as well as the internalization techniques (i.e., the drives, motives, and rationales) for the behavior that provides the adolescent with the capability and want to use the mechanical techniques (Higgins, Tewksbury \& Mustaine, 2007). The criminal behavior is the result of long-term exposure to lawviolating definitions. The longer a person holds positive attitudes toward breaking the law, the more likely one is to commit a criminal act.

Sutherland (1947) emphasized that effect of differential association varies by the individual based on priority, duration, and importance. Akers (1998) made the argument that individuals' intimate personal groups (i.e., the family and peers) will have the most 
impact on the individual. Therefore, peer association is important to differential association.

\section{Literature Review on Peer Association}

A longitudinal study was conducted from 1987-1990 on six high schools in California and three high schools in Wisconsin with 2000 students from grades 9-11. Erickson, Crosnoe and Dornbusch (2000) conducted a study on how adolescent deviant behavior of substance use and social bonds and differential association affect delinquency. The social bonds, parental attachment, parental supervision, teacher attachment, educational commitment and community involvement were all found to reduce adolescent involvement in delinquency and substance use (Erickson et al., 2000). A strong correlation was found for differential association. Having delinquent and substance-using friends increases one's chances of participating in this problem behavior (Erickson et al., 2000). The only difference based on gender was that males are more likely to participate in delinquency in substance use when associating with problem peers than are females who have problem peers (Erickson et al., 2000).

Neff and Waite (2007) conducted a study on how differential association/social learning theory impact substance abuse among male and female juvenile offenders. The study consisted of 5,000 incarcerated juveniles ( 89 percent males, 11 percent females) (Neff and Waite, 2007). Associating with peers who use drugs was found to be the strongest predictor of substance use for both genders (Neff and Waite, 2007). Males coming from a household where the use of alcohol is permitted were found to have a higher rate of substance use (Neff and Waite, 2007). Households that allow adolescent use of alcohol showed that earlier use of marijuana and alcohol was found for both 
genders (Neff and Waite, 2007). Males who are involved with gangs are linked to an early age of first use for alcohol and marijuana (Neff and Waite, 2007).

Miller (2009) examined the issue of differential association and peer susceptibility among 1,633 Mexican-American adolescents in grades 9 through 12. The study looked to see how differential association and peer susceptibility relate to delinquent adolescent behavior. Miller (2009) found adolescents, who are more susceptible to peer influence, have higher levels of delinquent behavior because of the influence of delinquent peers.

A study was conducted on social learning theory as it relates to nonmedical prescription drug (NMPD) use and alcohol. The study consisted of 465 college students from a midwestern university. The study found there was no difference in drug use between genders. However, associating with intimate partners or friends, who participate in NMPD result in greater use by the individual (Steele, Peralta and Elman, 2011). Higher use of NMPDS is associated with binge drinking, high-risk behavior and positive reinforcement of use (Steele, Peralta and Elman, 2011). Individuals, coming from a background of negative reinforcement or holding negative views towards NPMD and alcohol use, were found to not be significant (Steele, Peralta and Elman, 2011).

Pratt, Cullen, Sellers, Winfree, Madensen, Daigle, Fearn and Gau (2010) examined the empirical status of social learning theory through a meta-analysis. The sample consisted of 133 studies published from 1974 to 2003 that tested social learning/differential association theory alone, in relation to other theories, or by integrating more than one theory. The 133 studies were made up of 118,430 individual cases (Pratt et al., 2010). The meta-analysis predictors were differential association, definitions, differential reinforcement and modeling/imitation. 
The results of this study found an overall effect size of .23 for differential association predictors (Pratt et al., 2010). There is however, considerable variation among the differential association variables: peers' behavior $(.27)$, parents' behaviors (.14), others' behaviors (.10), peers' attitudes (.13), parents' attitudes (.03), others' attitudes (.05) (Pratt et al., 2010). The evidence shows that peers behavior is the strongest predictor and others' attitudes are the weakest predictor (Pratt et al., 2010). The overall effect for definition variables was found to be 0.22 (Pratt et al., 2010). The variable differential reinforcement overall effect was 0.10 (Pratt et al., 2010). The modeling/imitation variable overall effect was 0.10 (Pratt et al., 2010). The meta-analysis by Pratt et al. (2010) demonstrates that differential association was found to have the largest mean effect size in comparison to differential reinforcement, which had a weak effect size. This means association with deviant peers alone may not increases one's deviant behavior but that it leads to more opportunities to commit deviant acts (Pratt et al., 2010).

Differential association has import for steroids. Johnson et al. (1989) argued that steroids are distributed through peer associations. Yesalis, Streit, Vicary, Friedl, Brannon, and Buckley (1989) showed that peer association has a distinct influence on individual's body image that seems to translate into steroid use. Individuals that use steroids are likely to do so to improve their body image for acceptance by peers. Brower, Blow, and Hill (1994) showed that men that were at a high risk of using steroids also had higher numbers of steroid using acquaintances. While this is not exhaustive, this literature does provide some indication that differential association 
has import for steroids. In essence, they provide context for this behavior as others (i.e., Pratt et al., 2010) have shown that they provide for crime and delinquency. 


\section{CHAPTER III}

\section{Present Study}

The purpose of the present study is to examine the theoretical explanations of steroid use at different periods of adolescent's lives. The periods of life include in an adolescent's lifetime, 12 months, and 30 days. The hypotheses being tested in this thesis are: 1) low self-control increases the likelihood of adolescent steroid use, 2) differential association (ie., peer association) increases the likelihood of adolescent steroid use and 3) that high levels of self control and having friends who do not use steroids will result in adolescent steroid use going down. The reason for these two hypotheses is that no one has applied low self-control and differential association toward adolescent steroid use. Seeking to explain adolescent steroid use through the use of criminological theory can help in understanding why adolescents' use steroids. If criminological theory can explain why adolescents' use steroids, researchers can use the new information in creating prevention techniques to stop adolescent steroid use.

\section{Methods}

The data for this study comes from the $12^{\text {th }}$ grade survey of the 2009 Monitoring the Future Project Form 6. The purpose of the Monitoring the Future Project (MTF) is to understand changes in values, behaviors, and lifestyle orientations of the American youth. There are two specific tasks of the Monitoring the Future survey: (1) provide a systematic and accurate "description" of the youth population of interest in a given year, and to 
quantify the direction and rate of the changes taking place among them over time and (2) provide an analytic analysis that produces an "explanation" of the relationships and trends observed to exist (Johnston, Bachman, O'Malley, \& Schulenberg, 2009). The survey is conducted in 130 public and private high schools selected to provide an accurate cross-section of high school seniors throughout the United States.

The MTF survey is a nationally representative sample is produced through multistage random sampling procedure (Johnson et al., 2009). The first stage is selecting by geographic areas that are the primary sampling units (Johnston et al., 2009). All high schools contained in a well-defined geographic area are known as the primary sampling units (Murphy, 2008). The second stage is selection of schools based on the school (Johnston et al., 2009). In major metropolitan areas, more than one high school is selected yet in most areas only one high school is sampled. The process of selecting a high school is based on the probability of drawing a school that is proportionate to the size of its senior class (Johnston et al., 2009). The final stage is the student selection process (Johnston et al., 2009). Depending on the size of the school up to 350 seniors may be included in the data collection. If a school has less than 350 students the survey attempts to include all students (Johnston et al., 2009). Schools containing more than 350 students then the students are selected by randomly sampling classrooms or another random method that is convenient and unbiased (Johnston et al., 2009). A sampling weight is assigned to each respondent to account for variation in sample size from one school to another and for variations in selection probabilities occurring at earlier stages of sampling (Johnston et al., 2009). 
The student participation rate is between three-fourths to four-fifths of all $12^{\text {th }}$ graders sampled. The validity of self-report data for MTF is supported by the following factors: (1) a low non-response rate on the drug questions; (2) a large proportion admitting to some illicit drug use; (3) the consistency of findings across several years of the present study; (4) strong evidence of construct validity; (5) a close match between these data and the findings from other studies using other methods; and (6) the findings from several methodological studies which have used objective validation methods (Johnson et al., 2009). The accuracy of the sample has a confidence intervals of $+/-1.5$ percentage points or smaller (Johnson et al., 2009). This shows that if all schools and seniors participated the results of the sample would be estimated within 1.5 percentage points from the present sample findings 95 times out of 100 (Johnston et al., 2009).

The study consists of a total of 14,268 adolescents. The sex of the adolescents was $44.5 \%$ male and $49.1 \%$ female. The race of the students was $10 \%$ Black, $56.4 \%$ White, and $16.8 \%$ Hispanic. An additional $16.7 \%$ selected more than one race or did not answer the question. The median level of education completed by the parent included some level of college.

\section{Measures}

Dependent Measures

For this study three dependent measures were used to mirror the use of adolescent steroids. The first measure was "Have you used steroids in your lifetime?" The respondents used a dichotomous answer choice $(0=$ no, $1=$ yes $)$ to indicate lifetime steroid use. The second measure was "Have you used steroids in the last 12 months?" The respondents used a dichotomous answer choice $(0=$ no, $1=$ yes $)$ to indicate steroid 
use in the last 12 months. The third measure was "Have you used steroids in the last 30 days?" The respondents used a dichotomous answer choice $(0=$ no, $1=$ yes $)$ to indicate steroid use in the last 30 days.

\section{Independent Measures}

Based on previous research a number of items were used as independent measures, including age, sex, race, region 1, region 2, and region 3. Age was measured as $0=<18$ years of age and $1=>18$ years of age. The data for age was dichotomized already by the survey. Sex was measured as $0=$ female and $1=$ male. Black and White respondents were compared in the data for Race. This measure was coded as $0=$ White and $1=$ Black. According to the 2009 Monitoring the Future Project steroid use among Whites and Hispanics mirrored each other (Johnston et al., 2009, p. 184). This study focuses on African-American's and Whites for the variable race. The respondents area of the country were coded for region 1 as $0=$ all other regions and $1=$ Northeast region, region 2 as $0=$ all other regions and $1=$ North Central region and region 3 as $0=$ all other regions and $1=$ South region. The 2009 Monitoring the Future Project reported differences in drug use (marijuana, cocaine, and tranquilizers) by region of the country (Johnson et al., 2009, p. 93).

GPA was used as a measure of self-control. This is based on Hirschi (2004) redefining self-control as having the ability to understand the all of the possibilities of the potential costs of a particular act. The purpose of this being that having a higher GPA shows a level of commitment to school. National Institute on Drug Abuse (2003, p.6) reported in a model designed to prevent drug abuse that academic competence (i.e., GPA) is protective factor against drug abuse. Adolescents with a low GPA are showing the 
characteristics of low self-control because they are not showing the level of commitment to school needed have a high GPA and they do not see the potential costs this will have. The respondents indicated their GPA using a 9-point measure as follows: $1=\mathrm{D}$ (69 or Below), $2=\mathrm{C}-(70-72), 3=\mathrm{C}(73-76), 4=\mathrm{C}+(77-79), 5=\mathrm{B}-(80-82), 6=\mathrm{B}(83-86), 7=$ $\mathrm{B}+(87-89), 8=\mathrm{A}-(90-92), 9=\mathrm{A}(93-100)$. GPA can also be seen as a measure of intelligence. The view of GPA as a measure of low self-control is not a measure for everybody. The belief held here is that most adolescents must demonstrate tenacity when it comes toward school meaning that at an adolescent's GPA is result of hard work and commitment to school. According to Hirschi (2004) GPA is one of the six measures of the revised self-control.

Peer association was measured using the variable that asks the respondents: "Do you have friends who use steroids?" The respondents indicated their response using a dichotomous answer choice $(0=$ no, $1=$ yes $)$. Student's involvement in school athletic teams was also used as a measure of peer association. This variable asks the respondents: "Have you participated on a school athletic team in the last school year?" The respondents indicated their response using a dichotomous answer choice $(0=$ no, $1=$ yes). The Difficulty in gaining access to steroids was measured using the variable that asks the respondents: "Is it easy for you to get steroids?" The respondents indicated their response using a dichotomous answer choice $(0=$ no, $1=$ yes $)$.

Low self-control was also measured in this study using five variables asking questions about risk taking. The first variable asked respondents: "I get a real kick out of doing things that are a little dangerous." The respondents answered the question using a 5-point Likert scale $(1=$ disagree, $2=$ mostly disagree, $3=$ neither, $4=$ mostly agree and 
5 agree). The second variable asked respondents: "I like to test myself every now and then by doing something a little risky." The respondents answered the question using a 5-point Likert scale $(1=$ disagree, 2 = mostly disagree, $3=$ neither, $4=$ mostly agree and $5=$ agree). The third variable asked respondents: "I like to do frightening things." The respondents answered the question using a 5-point Likert scale $(1=$ disagree, $2=$ mostly disagree, $3=$ neither, $4=$ mostly agree and $5=$ agree). The fourth variable asked respondents: "I like new and exciting experiences, even if I have to break the rules." The respondents answered the question using a 5-point Likert scale $(1=$ disagree, $2=$ mostly disagree, $3=$ neither, $4=$ mostly agree and $5=$ agree). The fifth variable asked respondents: "I prefer friends who are exciting and unpredictable." The respondents answered the question using a 5-point Likert scale $(1=$ disagree, $2=$ mostly disagree, $3=$ neither, $4=$ mostly agree and $5=$ agree) .

Factor analysis was conducted on these five variables. It is a multivariate technique for identifying whether the correlations between a set of observed variables stem from their relationship to one or more latent variables in the data (Field, 2009). There are two main uses of factor analysis for this data set: (1) understand the structure of a set of variables and (2) to reduce a data set to a more manageable size while retaining as much of the original information as possible (Field, 2009). The most common form of factor analysis is exploratory factor analysis and is used to uncover the underlying structure of a relatively large set of variables (Garson, 2011). The reason it is the most common is because there is no prior theory (Garson, 2011). Analysts use factor loading to figure out the factor structure of the data (Garson, 2011). 
Varimax rotation is an orthogonal rotation of the factor axes to maximize the variance of the squared loadings of a factor on all variables in a factor matrix (Garson, 2011). A varimax rotation attempts to maximize the dispersion of loadings within factors (Field, 2009). Factor loading is explains the relationship between the variables and the factors (Garson, 2011). A factor loading of .5 or higher means there is a significant relationship and should be retained all other values should be dismissed. The varimax rotation loads a small number of variables highly onto each factor resulting in more interpretable clusters (Field, 2009). It is the most common rotation option. The varimax rotation results make it as easy as possible to determine each variable with a single factor (Garson, 2011). The factor analysis resulted in one component being extracted. This became known as the variable self-control.

Factor extraction is used to determine what factors are of substantive importance (Field, 2009). The eigenvalue is used in factor extraction and is a factor that measures the variance in all the variables that are accounted for by that factor (Garson, 2011). For instance, researchers may use 18 variables when looking at steroid users for a research project. The eigenvalue helps determine which variables are important when it comes to explaining the variance of those variables. If the eigenvalue is greater than one of each variable then the researcher will keep that variable and throw out the rest of the variables. This is known as Kaiser's rule (Field, 2009). 
Table 1: Total Variance Explained

\begin{tabular}{lrrrrrr}
\hline \hline Component & \multicolumn{3}{c}{ Initial Eigenvalues } & \multicolumn{3}{c}{ Extraction Sums of Squared Loadings } \\
\cline { 2 - 7 } & Total & $\begin{array}{c}\text { \% of } \\
\text { Variance }\end{array}$ & $\begin{array}{c}\text { Cumulative } \\
\%\end{array}$ & Total & $\begin{array}{c}\text { \% of } \\
\text { Variance }\end{array}$ & $\begin{array}{c}\text { Cumulative } \\
\%\end{array}$ \\
\hline 1 & 3.144 & 62.883 & 62.883 & 3.144 & 62.883 & 62.883 \\
2 & .671 & 13.413 & 76.296 & & & \\
3 & .428 & 8.553 & 84.849 & & & \\
4 & .404 & 8.075 & 92.923 & & & \\
5 & .354 & 7.077 & 100.000 & & & \\
\hline \hline
\end{tabular}

Extraction Method: Principal Component Analysis.

Figure 1: Scree Plot

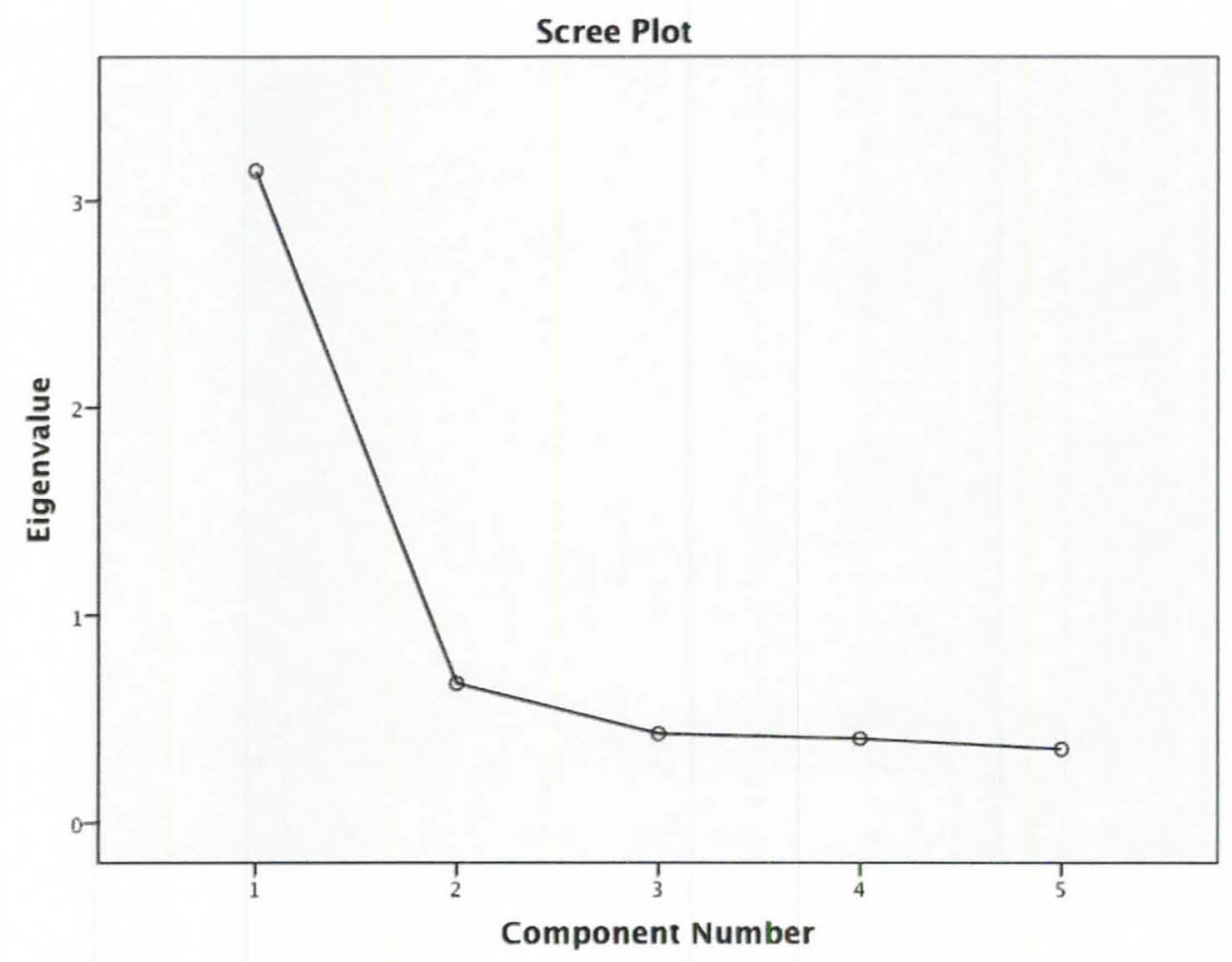




\begin{tabular}{lcc}
\hline \hline & \multicolumn{2}{c}{ Component } \\
\cline { 2 - 3 } & \multicolumn{1}{c}{1} \\
\hline Dangerous & .827 \\
Risky & .825 \\
Frightening & .816 \\
Break Rules & .811 \\
Friends Exciting & .675 \\
\hline \hline
\end{tabular}

Extraction Method: Principal Component Analysis.

a. 1 components extracted.

A factor analysis was conducted on the 5 items with a varimax rotation. All five components had eigenvalues over 1 and in combination explained for $62.88 \%$ of the variance. Given the large sample size and the convergence of the scree plot and Kaiser's criterion on one component is the only component that will be retained for the final analysis. Table 2 shows the factor loadings after rotation. The items that cluster on the one component represent all five items because each one has a factor loading over .5 . This creates the one factor known as low self-control.

Table 3: Reliability Statistics

\begin{tabular}{rrrr}
\hline \hline Cronbach's Alpha & $\begin{array}{c}\text { Cronbach's Alpha Based on } \\
\text { Standardized Items }\end{array}$ & N of Items \\
\hline .852 & .851 & 5 \\
\hline \hline
\end{tabular}

Cronbach's Alpha is used to measure the internal consistency of items in a scale (Garson, 2011). It measures the extent to which item responses obtained at the same time that highly correlate to each other (Garson, 2011). Cronbach's alpha calculates two things: (1) the variance within the item and (2) the covariance between any two items on the scale (Field, 2009). The universal alpha score used for a set of items to be considered 
a scale should be .80 or higher (Garson, 2011). The five measures all had a high reliability with Cronbach's Alpha of $\mathbf{8 5 2}$. The reliability shows the consistency of the measure (Field, 2009).

\section{Analysis Plan}

This analysis uses logistic regression in order to explain how low-self control and differential association can explain adolescent steroid use. According to the hypothesis adolescent steroid use is predicted by associating with peers who use steroids, how easy it is to obtain steroids and participating in risk taking and/or impulsive behavior.

The first step is to present the descriptive statistics. The mean is a simple statistical model of the center of a distribution of scores (Field, 2009). The mean can explain the average number of adolescent steroid users. The standard error is the standard deviation of sample means (Field, 2009). Standard deviation is an estimate of the average variability of a set of data measured in the same units of measurement as the original data and is the square root of the variance (Field, 2009). Kurtosis is the amount of curve peakedness in any distribution (Champion \& Hartley, 2010). This can shown in the study in the frequency of how adolescents responded to questions pertaining to steroid use the kurtosis would be negative. If adolescents disproportionately responded by saying they did not use steroids the distribution would have a negative kurtosis meaning it would have a relatively thin tail and be flatter than normal (Field, 2009). Skewness is the distribution shape where scores accumulate in one end of the distribution or the other (Champion \& Hartley, 2010). The skewness could be positive where the scores accumulate in the left tail of the curve or negative where scores accumulate in the right tail of the curve (Champion \& Hartley, 2010). Skewness can show in this study if 
the distribution is positive or negative in terms of adolescent steroid use. If the distribution were assumed to be normal the kurtosis is less than or equal to 10 and skewness is less than or equal to 3 . When the sample consists of dichotomous variables, there is no standard deviation.

Analyzing the data using logistic regression, an extension of simple regression that can predict categorical outcomes based on predictor variables (Field, 2009). Logistic regression contains an outcome variable that is known as a categorical variable and predictor variables that are either continuous or categorical (Field, 2009). Logistic regression can be used for five reasons: (1) to predict a categorical dependent variable on the basis of continuous and/or categorical independents, (2) to determine the effect size of the independent variable on the dependent, (3) to rank independent variables on relative importance, (4) to measure interaction effects and (5) to understand the impact of covariate control variables (Garson, 2011). This is important to this study because it helps explain the effect size of the independent variable on the dependent variable.

The use of logistic regression is important to this study because it overcomes the limitations of OLS regression. Logistic regression does not assume there is a linear relationship between the dependent and the independent variables (Garson, 2011). This is important to this study because it allows one to test for a linear relationship between any continuous predictors and the logit of the outcome variable (Field, 2009). The dependent variable does not have to be normally distributed (Garson, 2011). There does not have to be homoscedascity with the dependent variable and each level of the independent variables (Garson, 2011). The assumption of homoscedasticity is violated with dichotomous dependent variable (Champion \& Hartley, 2010). The value for the 
error term will change with the values of the independent variables (Champion \& Hartley, 2010). The probability of the dependent variable being a "0" or "1", impacts the error term because the dependent variable is dichotomous (Champion \& Hartley, 2010). The error term is heteroscedatic when the variance of the error term is not constant (Champion \& Hartley, 2010). It is not assumed that there are normally distributed error terms (Garson, 2011). The independent variables are not required to be interval or unbounded (Garson, 2011). Having unbounded independent variables, helps explain the probability of the outcome based on the dependent variable (Champion \& Hartley, 2010).

The final step is interpreting the logistic regression results. The overall significance level is found by using the likelihood ratio statistic and the chi-square test variation with the $-2 \log$ likelihood (Champion \& Hartley, 2010 and Field, 2009). The level of significance was set at .05 . The amount of variance in the dependent variable that is explained by the model can be found using Cox and Snell's $\mathrm{R}^{2}$ is a version of the coefficient of determination for logistic regression (Field, 2009). Nagelkerke $\mathrm{R}^{2}$ is a variation of the Cox and Snell's $\mathrm{R}^{2}$. This statistic overcomes the problem of not being able to reach the maximum value of 1 (Field, 2009).

Determining which independent variables are statistically significant is done using the Wald statistic. It explains whether the $b$ coefficient for that predictor is significantly different from zero (Field, 2009). An independent variable is statistically significant if the probability is below .05 (Champion \& Hartley, 2010).

The value of the odds ratio is critical to the interpretation of logistic regression. The odds ratio interprets the unstandardized effects of the independent variables that were 
found to be statistically significant. It is an indicator of the change in odds resulting from a unit change in the predictor (Field, 2009). 


\section{CHAPTER IV}

\section{RESULTS}

Table 1 presents the descriptive statistics for the measures used in this study. The variable "Age" shows that $44.74 \%$ answered the question as " $<18$ years of age." The variable "Sex" shows that $47.68 \%$ answered the question as "Male." The variable "Race" $15.92 \%$ answered the question as "Black." Based on area of the country $23.93 \%$ live in the "Northeast Region", 24.39\% live in the "North Central Region". $30.90 \%$ live in the "South Region" and $20.78 \%$ said they live in the "West Region." The variable "self-control" has a mean of 16.36. The variable "GPA" has a mean of 6.51 that shows the average GPA is between a " $\mathrm{B}$ " and " $\mathrm{B}+$." $56.00 \%$ of the respondents stated they participated on a school athletic team in the last school year. $20.00 \%$ of the respondents stated that they have friends who use steroids. $40.58 \%$ of the adolescents said that it is easy for them to obtain steroids. $1.96 \%$ of the sample said that they have taken steroids in their lifetime and $1.24 \%$ said they have taken steroids in the last twelve months. $0.81 \%$ said they have taken steroids in the last thirty days. 
Table 4 Descriptive Statistics

\begin{tabular}{|c|c|c|c|c|c|c|c|}
\hline Measure & Min & Max & Mean/Percentage & Total N & SD & Skew & Kurtosis \\
\hline Age & $0(1026)$ & $1(1306)$ & $44.74 \%$ & 2311 & - & .21 & -1.96 \\
\hline Sex & $0(1183)$ & $1(1078)$ & $47.68 \%$ & 2261 & - & .09 & -1.99 \\
\hline Race & $0(1320)$ & $1(250)$ & $15.92 \%$ & 1570 & - & 1.86 & 1.48 \\
\hline $\begin{array}{c}\text { Northeast } \\
\text { Region }\end{array}$ & $0(1812)$ & $1(570)$ & $23.93 \%$ & 2382 & -- & 1.22 & -0.51 \\
\hline $\begin{array}{c}\text { North } \\
\text { Central } \\
\text { Region }\end{array}$ & $0(1801)$ & $1(581)$ & $24.39 \%$ & 2382 & -- & 1.19 & -0.58 \\
\hline $\begin{array}{c}\text { South } \\
\text { Region }\end{array}$ & $0(1646)$ & $1(736)$ & $30.90 \%$ & 2382 & -- & .83 & -1.32 \\
\hline $\begin{array}{c}\text { West } \\
\text { Region }\end{array}$ & $0(1887)$ & $1(495)$ & $20.78 \%$ & 2382 & - & 1.44 & .08 \\
\hline $\begin{array}{c}\text { Self- } \\
\text { Control }\end{array}$ & 5 & 25 & 16.36 & 2066 & 5.01 & -0.24 & -0.638 \\
\hline $\begin{array}{c}\text { What is } \\
\text { Your } \\
\text { GPA }\end{array}$ & 1 & 9 & 6.51 & 2288 & 1.93 & -0.57 & -.38 \\
\hline Athletics & $0(1026)$ & $1(1306)$ & $56.00 \%$ & 2332 & -- & -.24 & -1.94 \\
\hline $\begin{array}{c}\text { Friends } \\
\text { Who Use } \\
\text { Steroids }\end{array}$ & $0(1652)$ & $1(413)$ & $20 \%$ & 2065 & -- & 1.50 & 0.25 \\
\hline $\begin{array}{c}\text { Is it Easy } \\
\text { for You to } \\
\text { Get } \\
\text { Steroids }\end{array}$ & $0(1366)$ & $1(933)$ & $40.58 \%$ & 2299 & - & .38 & -1.85 \\
\hline $\begin{array}{c}\text { Lifetime } \\
\text { Steroid } \\
\text { Use }\end{array}$ & $0(2048)$ & $1(41)$ & $1.96 \%$ & 2089 & -- & 6.93 & 46.08 \\
\hline $\begin{array}{c}\text { Steroid } \\
\text { Use in the } \\
\text { Last 12 } \\
\text { Months }\end{array}$ & $0(2063)$ & $1(26)$ & $1.24 \%$ & 2089 & - & 8.80 & 75.54 \\
\hline $\begin{array}{c}\text { Steroid } \\
\text { Use in the } \\
\text { Last 30 } \\
\text { Days }\end{array}$ & $0(2071)$ & $1(17)$ & $0.81 \%$ & 2088 & -- & 10.96 & 118.12 \\
\hline
\end{tabular}

Table 2 presents the logistic regression analysis that examined the links between the independent measures and lifetime steroid use without a doctor prescription. If the respondent's sex was male they are 14.27 times more likely to use steroids in their lifetime. As a respondent's GPA increases by one unit their 
chances of steroid use decreased $(b=-0.29, \operatorname{Exp}(b)=0.75)$. Respondents who had friends who use steroids are 5.11 times more likely to use steroids in their lifetime. The model chi-square statistic indicates the difference between the model as it currently stands and the model when only the constant was included. The chi-square value is significant at the .05 level and this indicates that the model is predicting lifetime steroid use better than it was with only the constant included. The $-2 \log$ likelihood of 144.63 indicates that there is some unexplained variance in the model. The Cox and Snell $\mathrm{R}^{2}$ indicates that the variables of sex, GPA and friends who use steroids explain for 3 percent of the variance for lifetime steroid use while Nagelkerke $R^{2}$ value indicates that these variables explain 25 percent of the variance in lifetime steroid use.

Table 5 Logistic Regression Analysis: Lifetime Steroid Use

\begin{tabular}{|c|c|c|c|}
\hline Measure & $B$ & SE & $\operatorname{Exp}(b)$ \\
\hline Age & -0.75 & 0.60 & 0.47 \\
\hline Sex & $2.66^{*}$ & 1.04 & 14.27 \\
\hline Race & 0.37 & 0.73 & 1.44 \\
\hline Region 1 & 0.48 & 0.96 & 1.61 \\
\hline Region 2 & 0.89 & 0.87 & 2.43 \\
\hline Region 3 & 0.83 & 0.84 & 2.30 \\
\hline Self-Control & -.01 & 0.05 & 0.99 \\
\hline GPA & $-0.29^{*}$ & 0.13 & 0.75 \\
\hline Athletics & -.09 & 0.52 & 5.11 \\
\hline $\begin{array}{c}\text { Friends Who Use } \\
\text { Steroids }\end{array}$ & $1.63^{*}$ & 0.54 & 2.35 \\
\hline $\begin{array}{c}\text { Is it Easy for You to Get } \\
\text { Steroids }\end{array}$ & 0.86 & 0.57 & \\
\hline Chi-Square $=44.14^{*}$ & & & \\
\hline-2 log likelihood $=$ & & & \\
\hline 144.63 & & & \\
\hline Cox and Snell $\mathbf{R}^{2}=.03$ & & & \\
\hline Nagelkerke $\mathbf{R}^{2}=0.25$ & & & \\
\hline
\end{tabular}

${ }^{*} \mathrm{p}<.05$

Table 3 presents the logistic regression analysis that examined the links between the independent measures and steroid use in the last twelve months. Males were 8.45 times more likely to use steroids in the last twelve months. As a respondents GPA increases by one unit their chances of using steroids in the last 
twelve months decreases $(b=-0.46, \operatorname{Exp}(b)=0.63)$. Respondent's who have friends who use steroids are 6.25 times more likely to have used steroids in the last twelve months. The model chi-square statistic indicates the difference between the model as it currently stands and the model when only the constant was included. The chi-square value is significant at the .05 level and this indicates that the model is predicting lifetime steroid use better than it was with only the constant included. The $-2 \log$ likelihood of 98.40 indicates that there is some unexplained variance in the model. The Cox and Snell $\mathrm{R}^{2}$ indicates that the variables of sex, GPA and friends who use steroids explain for 3 percent of the variance for steroid use in the last 12 months while Nagelkerke $\mathrm{R}^{2}$ value indicates that these variables explain 29 percent of the variance in steroid use in the last 12 months.

Table 6 Logistic Regression Analysis: Steroid Use in the Last 12 Months

\begin{tabular}{|c|c|c|c|}
\hline Measure & $b$ & SE & Exp $(b)$ \\
\hline Age & -0.62 & 0.72 & 0.54 \\
\hline Sex & $2.13^{*}$ & 1.07 & 8.45 \\
\hline Race & 0.32 & 0.90 & 1.38 \\
\hline Region 1 & -0.49 & 1.28 & 0.61 \\
\hline Region 2 & 0.70 & 0.92 & 2.02 \\
\hline Region 3 & 0.23 & 0.93 & 1.26 \\
\hline Self-Control & -0.3 & 0.06 & 0.97 \\
\hline GPA & $-0.46^{*}$ & 0.16 & 0.63 \\
\hline Athletics & -0.07 & 0.64 & 6.93 \\
\hline $\begin{array}{c}\text { Friends Who Use } \\
\text { Steroids }\end{array}$ & $1.83^{*}$ & 0.68 & 2.68 \\
\hline $\begin{array}{c}\text { Is it Easy for You to Get } \\
\text { Steroids }\end{array}$ & 0.99 & 0.72 & \\
\hline Chi-Square $=37.25$ & & & \\
\hline-2 log likelihood $=98.40$ & & & \\
\hline Cox and Snell $\mathbf{R}^{2}=.03$ & & & \\
\hline Nagelkerke $\mathbf{R}^{2}=0.29$ & & & \\
\hline * $\mathrm{p}<.05$ & & & \\
\hline
\end{tabular}

Table 4 presents the logistic regression analysis that examined the links between the independent measures and steroid use in the last thirty days. As a respondent's GPA increases by one unit their chances of using steroids in the last 
thirty days decreases $(b=-0.5, \operatorname{Exp}(b)=0.61)$. Respondents who have friends who use steroids are 8.04 times more likely to have used steroids in the last 30 days. ${ }^{1}$ The model chi-square statistic indicates the difference between the model as it currently stands and the model when only the constant was included. The chi-square value is significant at the .05 level and this indicates that the model is predicting lifetime steroid use better than it was with only the constant included. The $-2 \log$ likelihood of 85.41 indicates that there is some unexplained variance in the model. The Cox and Snell $\mathrm{R}^{2}$ indicates that the variables of GPA and friends who use steroids explain for 2 percent of the variance for steroid use in the last 30 days while Nagelkerke $R^{2}$ value indicates that these variables explain 28 percent of the variance for steroid use in the last 30 days.

${ }^{1} \mathrm{~A}$ cross tabulation was performed with steroid use in the last 30 days and sex. Fourteen male and 3 female juveniles stated they had used steroids in the last 30 days. Thus, the majority of adolescent steroid users were male. This result explains why sex was found not to be a significant predictor of steroid use in the last 30 days fot artodesabutation was performed with steroid use in the last 30 days and sex. Fourteen male and 3 female juveniles stated they had used steroids in the last 30 days. Thus, the majority of adolescent steroid users were male. This result explains why sex was found not to be a significant predictor of steroid use in the last 30 days for adolescents. 
Table 7 Logistic Regression Analysis: Steroid Use in the Last 30 Days

\begin{tabular}{|c|c|c|c|}
\hline Measure & $b$ & SE & $\operatorname{Exp}(b)$ \\
\hline Age & -0.40 & 0.76 & 0.67 \\
\hline Sex & 1.91 & 1.09 & 6.72 \\
\hline Race & 0.55 & 0.91 & 1.73 \\
\hline Region 1 & -0.57 & 1.29 & 0.56 \\
\hline Region 2 & 0.38 & 0.96 & 1.47 \\
\hline Region 3 & -0.13 & 0.98 & 0.88 \\
\hline Self-Control & -.063 & .07 & 0.94 \\
\hline GPA & $*_{-0.5}$ & 0.17 & 0.61 \\
\hline Athletics & .508 & 0.75 & 1.66 \\
\hline FrndUseStrd & $* 2.10$ & 0.76 & 8.04 \\
\hline DiffStrd & 0.65 & 0.75 & 1.92 \\
\hline Chi-Square $=31.29$ & & & \\
\hline-2 log likelihood $=85.41$ & & & \\
\hline Cox and Snell $\mathbf{R}^{2}=.02$ & & & \\
\hline Nagelkerke $\mathbf{R}^{2}=0.28$ & & & \\
\hline
\end{tabular}

${ }^{*} \mathrm{p}<.05$ 


\section{CHAPTER V}

\section{DISCUSSION}

The purpose of this study was to determine what influences adolescent steroid use. The hypotheses of the study were: (1) low self-control increases the likelihood of adolescent steroid use, (2) differential association increases the likelihood of adolescent steroid use and (3) that high levels of self control and having friends who do not use steroids will result in adolescent steroid use going down. The findings show that low self-control and peer association are related to adolescent steroid use. The results show that having high level of self control and having friends who do not use steroids reduce the likelihood of adolescent steroid use. It appears that peer association has a greater impact on adolescent steroid use than low self-control. However the scales used to measure the impact of peer association and low self-control are not equivalent it is difficult to determine which variable's impact is greater.

\section{Self-Control Theory}

This research investigated two untested theories on how criminology can explain adolescent steroid use. The first measure was on how low-self control explains adolescent steroid use. According to Gottfredson and Hirschi (1990) low self-control occurs when individuals cannot withstand the lure of pleasure because they can't see the long-term consequences. Displaying such characteristics can affect one's ability to gauge 
the consequences of their actions; thus they may see just the pleasure and not the pain of their decision. Such individuals who suffer from low self-control share common characteristics: impulsiveness and insensitivity; an attraction to easy and simple tasks, risks, and physical activities (Gottfredson \& Hirschi, 1990; Higgins \& Mahoney, 2010).

Previous research has shown a link between adolescent drug use and low-self control (Sorenson \& Brownfield, 1995; Higgins et al., 2009; Ragan \& Beaver, 2010). The measure of GPA is indicator of self-control because it shows ability to understand the potential cost it has on an individual's future performance. A student's GPA is representative of the social bond one has in the commitment and belief in scholastic achievement. The findings from this study found a student's GPA to be statistically significant at explaining adolescent steroid use. This measure is an example of low selfcontrol. School performance is a measure of the social bond to commitment. The GPA of a student shows a link in the time and commitment one has to school. Adolescents who display low-self control show less commitment to school as indicated by a low GPA. The research results reveal that the lower the GPA, the more likely the adolescent will use steroids.

\section{Differential Association}

The second theory tested was on how does peer association explain adolescent steroid use. As defined by Sutherland (1947), the process of learning of such behavior comes through differential association such as intimate personal groups. Adolescents within an intimate personal group either approve or disapprove of criminal behavior. Adolescents learn that the use of steroids is good or bad by the learned "definitions" (rationalizations and attitudes) of the group (Akers \& Sellers, 2009). 
Previous research has shown a link between peer association and adolescent drug use (Erickson et al., 2000; Neff and Waite, 2007; Pratt et al., 2010). Pratt et al., (2010) found that peer association was the strongest link to drug use across all variables. The findings from this study found having friends who use steroids to be a statistically significant predictor of adolescent steroid use. It appears that peers sponsor adolescent steroid use. Among adolescents intimate personal groups hold strong influence upon steroid use. This shows that peer association is an important predictor of adolescent steroid use.

Sex

Previous research has shown that males use steroids at much higher rate then women (Durant et al., 1995; Yesalis et al., 1997; Congeni \& Miller, 2002). Consistent with the previous research, findings from this study reveal that adolescent males were more likely to use steroids. Use of steroids among adolescents appears to happen at a higher rate among males.

\section{Policy}

The research findings reveal that efforts to intervene and prevent adolescent steroid use should focus on strengthening the adolescent's self-control, be aware of peer group influence on steroid use, and males are more likely to engage in steroid use. People need to be made aware that adolescent's who suffer from low self-control are at a greater likelihood of using steroids. Parents and school administrators can be made aware rather easily of who could be suffering from low self-control simply by looking at a student's GPA. A student with a low GPA is not showing the level of commitment and focus needed to succeed at school and this may come from having low self-control. In 
turn, low self-control can lead to steroid use. Strengthening the social bond of commitment to school can help prevent steroid use. The National Institute on Drug Abuse (2003) puts emphasis on programs with early intervention. The Caring School Community Program is an example of an early intervention program. The program places emphasis on improving students' ties to the community and stronger connection to school.

Parents should be aware if their child is associating with friends who believe that steroid use is beneficial are at a greater risk for use. Parents and school administrators need to be more aware of adolescent steroid use and that peer group association sponsors the use of steroids by others. Schools need to provide educational programs on the dangers of steroid use to combat the belief system of intimate personal groups. The Adolescents Training and Learning to Avoid Steroids (ATLAS) is a program used to help reduce the risk factors for steroids and other drugs by providing healthy sports nutrition and strength-training advice (National Institute on Drug Abuse, 2003, p. 33). Parental involvement also takes place in the form of parent-student homework and parents are provided a booklet, Family Guide to Sports Nutrition (National Institute on Drug Abuse, 2003 p. 330).

Male adolescents are far more likely to use steroids than there female counterparts. School administrators and parents should be much more aware of males who are showing physical signs of steroids use. The most common side effects for males are: decreased testosterone production, decreased spermatogenesis, and testicular atrophy (Elliot \& Goldberg, 2000; American Academy of Pediatrics, 1997; Bagatell \& Bremner, 1996; Harlan, Grillo, Cornoni-Huntley \& Leaverton, 1979). The Coping Power is a 
program targeted for high-risk aggressive adolescent males (National Institute on Drug Abuse, 2003, p. 32). The program trains children and family on how to cope with anxiety and anger, control impulsive behavior, develop academic and social skills, and develop problem solving skills to use at school and home (National Institute on Drug Abuse, 2003, p. 32).

\section{Limitations}

The Monitoring the Future Survey is based on the self-report of adolescent behavior. In self-report surveys there is an issue of the reluctance to admit illegal behavior (Maxfield \& Babbie, 2009). This could present itself in this survey in adolescents underreporting their use of steroids. The rate of steroid use could be higher than indicated by the survey results. Steroid use could be behavior that the respondent is more likely to conceal then admit because it is a criminal act.

The Monitoring the Future Survey does not place emphasis on steroid use in comparison to other drugs. There is only one category specifically committed to steroids that contains six questions. For drugs other than steroids the Monitoring the Future Survey examines such isssues as, exposure and attitudes towards cigarette ads, how cigarettes purchased, difficulty in quitting, future use of substances, friends attitudes about your use and grade of first use. A survey specifically devoted to steroid use could pursue these issues and open ended and or interview questions among steroid users. This would result in a more complete understanding adolescent steroid use and a further test of the findings of this study regarding self-control and peer association.

A limitation of the study is that it may overestimate the number of adolescent steroid users. For example it would be possible for one respondent to have been included 
in all three measures of steroid use. The view of GPA as a measure of low self-control is not a measure for everybody. GPA can also be viewed as a measure of intelligence. The belief held here is that most adolescents must demonstrate tenacity when it comes toward school meaning that an adolescent's GPA is a result of hard work commitment to school. According to Hirschi (2004) GPA is one of the six measures of the revised self-control.

There are only two measures of differential associaiton in this study. There could be more more measures of differential assocation added to this study. These two measures how ever do capture some of the constructs of peer association. There are only two measures of low self-control in this study. However, both of these measures have enough to capture the constructs for measuring low self-control. The low self-control measure is representative of Gottfredson and Hirschi's 1990 defintion for low selfcontrol. Wood, Pfefferbaum and Arneklev (1993) used Gottfredson and Hirschi's 1990 measure and found self-control to be a measure for delinquency. The measure of GPA represents Hirschi (2004) redefinition of low self-control. 


\section{REFERENCES}

Akers, R. L., \& Sellers, C. S. (2009). Criminological Theories: Introduction, Evaluation and Application. New York City: Oxford University Press.

Akers, R. (1998). Social Learning and Social Structure: A General Theory of Crime and Deviance. Boston: Northeastern University Press.

American Academy of Pediatrics. (1997). Adolescents and Anabolic Steroids: A Subject Review. Pediatrics , 904-908.

Anderson, W. A., Albrecht, M. A., McKeag, D. B., Hough, D. O., \& McGrew, C. A. (1991). A National Survey of Alcohol and Drug Use by College Athletes. The Physician and Sports Medicine, 19 (2), 91-104.

Avary, D., \& Pope, H. J. (2000). Anabolic-Androgenic Steroids as a Getway to Opioid Dependence. New England Journal of Medicine , 342, 1532.

Bagatell, C. J., \& Bremner, W. J. (1996). Androgens in Men-Uses and Abuses. Drug Therapy, 334, 707-713.

Baker, J. 0. (2010). The Expression of Low Self-Control as Problematic Drinking in Adolescents: An Integrated Control Perspective. Journal of Criminal Justice , 237-244.

Bamberger, M., \& Yaeger, D. (1997, April 14). Over the Edge. Sports Illustrated , 86 (15), pp. 60-70. 
Beaver, K. M., Vaughn, M. G., DeLisi, M., \& Wright, J. P. (2008). Anabolic-Androgenic Steroid Use and Involvement in Violent Behavior in a Nationally Representative Sample of Young Adult Males in the United States. American Journal of Public Health , 2185-2187.

Bowman, S. J., Tanna, S., Fernando, S., Ayodeji, A., \& Weatherstone, R. M. (1989). Anabolic Steroids and Infarction. British Medical Journal , 299, 632.

Brower, K. J., Blow, F. C., \& Hill, E. M. (2002). Risk factors for anabolic-androgenic steroid

use in men. Journal of Psychiatric Research, 28, 369-380.

Buckely, W. E., Yesalis, C. E., \& Bennell, D. L. (1993). A Study of Anabolic Steroid Use at the Secondary School Level: Recommendations for Prevention. In C. E. Yesalis, Anabolic Steroids in Sports Exercise (pp. 71-86). Champaign, IL: Human Kinetics Press, Inc.

Cabasso, A. (1994). Pelosis Hepatis in a Young Adult Bodybuilder. Medicine and Science in Sports and Exercise , 26, 2-4.

Champion, D. J., \& Hartley, R. D. (2010). Statistics for Criminal Justice and Criminology. Upper Saddle River: Pearson Education, Inc.

Choi, P. Y., \& Pope, H. G. (1994). Violence Toward Women and Illict AndrogenicAnabolic Steroid Use. Ann Clin Psychiatry , 6, 21-25.

Congeni, J., \& Miller, S. (2002). Supplements and drugs used to enhance athletic performance. The Pediatric Clinics of North America , 435-461.

Conner, B. T., Stein, J. A., \& Longshore, D. (2009). Examining Self-Control as a Multidimensional Predictor of Crime and Drug Use in Adolescents with 
Criminal Histories. The Journal of Behavioral Health Services \& Research , 36 (2), 137-149.

Cooper, C. J., Noakes, T. D., Dunne, T., Lambert, M. I., \& Rochford, K. (1996). A High Prevalence of Abnormal Personality Traits in Chronic Users of AnabolicAndrogenic Steroids. British Journal of Sports Medicine , 39, 246-250.

Creagh, T. M., Rubin, A., \& Evans, D. J. (1988). Hepatic Tumors Induced by Anabolic Steroids in an Athlete. Journal of Clinical Pathology, 41, 441-443.

De Li, S. (2005). Race, Self-Control, and Drug Problems Among Jail Inmates. Journal of Drug Issues , 645-664.

Denham, B. E. (2009). Steroid Use: Adolescents Associaton Between Narcotic Use and Anabolic-Androgenic Steroid Use Among American Adolescents. Substance Use \& Misuse , 2043-2061.

Dickerman, R. D., Schaller, F., Prather, I., \& McConathy, W. J. (1995). Sudden Cardiac Death in a 20-Year-Old Bodybuilder Using Anabolic Steroids. Cardiology , 86, $172-173$

Durant, R. H., Escobedo, L. G., \& Heath, G. W. (1995). Anabolic-Steroid Use, Strength Training, and Multiple Drug Use Among Adolescents in the United States. Pediatrics , 23-28.

Durant, R. H., Vaughn, I., Ashworth, C. S., Newman, C., \& Slavens, G. (1993). Use of Multiple Drugs Among Adolescents Who Use Anabolic Steroids. The New England Journal of Medicine , 922-926. 
Elliot, D. L., \& Goldberg, L. (2000). Women and Anabolic Steroids. In C. E. Yesalis, Anabolic Steroids in Sport and Exercises (pp. 225-246). Champaign, I: Human Kinetics.

Erickson, K. G., Crosnoe, R., \& Dornbusch, S. M. (2000). A Social Process Model of Adolescent Deviance: Combining Social Control and Differnential Association Perspectives. Journal of Youth and Adolescence, 29 (4), 395-425.

Evans, T. D., Cullen, F. T., Burton Jr., V. S., Dunaway, G., \& Benson, M. L. (1997). The Social Consequences of Self-Control: Testing the General Theory of Crime. Criminology, 35 (3), 475-504.

Ferenchick, G. S., \& Adelman, S. (1992). Myocardial Infarction Associated with Anabolic Steroid Use in a Previously Healthy 37-Year-Old Weight Lifter. American Heart Journal, 124, 507-508.

Field, A. (2009). Discovering Statistics Using SPSS (Vol. III). London, England: SAGE Publications Ltd.

Fisher, M., Appleby, M., Rittoo, D., \& Cotter, L. (1996). Myocardial Infarction with Extensive Intracoronary Thrombus Induced by Anabolic Steroids. British Journal of Clinical Practice, 50, 222-223.

Franke, W. W., \& Berendonk, B. (1997). Hormonal Doping and Androgenization of Athletes: A Secret Program of the German Democratic Republic Government. Clinical Chemistry , 43, 1262-1279.

Garson, G. D. (2011, December 12). Logistic Regression: Statnotes, from North Carolina State University, Public Administration Program. Retrieved February 
7, 2012, from North Carolina State University:

http://faculty.chass.ncsu.edu/garson/PA765/logistic.htm

Goldman, B. (1985). Liver Carcinoma in an Athlete Taking Anabolic Steroids. Journal of the American Osteopathic Association, 85, 86.

Gottfredson, M. R., \& Hirschi, T. (1990). A General Theory of Crime. Stanford, California: Stanford University Press.

Gruber, A., \& Pope, H. (2000). Psychiatric and Medical Effects of Anabolic Androgenic Steroid Use in Women. Psychotherapy and Psychosomatics, 69, $19-26$.

Harlan, W. R., Grillo, G. P., Cornoni-Huntley, J., \& Leaverton, P. (1979). Secondary Sex Characteristics of Boys 12 to 17 Years of Age: the U.S. Health Examination Survey. Journal of Pediatrics , 95, 293.

Higgins, G. E. (2005). Can Low Self-Control Help with the Understanding of the Software Piracy Problem? Deviant Behavior , 26, 1-24.

Higgins, G. E., Mahoney, M., \& Ricketts, M. L. (2009). Nonsocial Reinforcement of the Nonmedical Use of Prescription Drugs: A Partial Test of Social Learning and Self-Control Theories. Journal of Drug Issues , 949-964.

Higgins, G. E., Tewksbury, R., \& Mustaine, E. E. (2007). Sports Fan Binge Drinking: An Examination Using Low Self-Control and Peer Association. Sociological Spectrum , 389-404.

Higgins, G. E., Wolfe, S. E., \& Marcum, C. D. (2008). Digital piracy: An examination of three

measurements of self-control. Deviant Behavior, 29, 440-460. 
Huie, M. J. (1994). An Acute Myocardial Infarction Occurring in an Anabolic Steroid User. Medicine and Science in Sports and Exercise , 26, 408-413.

Humphreys, B. R., \& Ruseski, J. E. (2011). Socio-economic determinants of adolescent use of performance enhancing drugs: Evidence from the YRBSS. The Journal of Socio-Economics , 208-216.

Johnson, M. D., Jay, M. S., Shoup, B., \& Rickert, V. I. (1989). Anabolic Steroid Use by Male Adolescents. Pediatrics , 921-924.

Johnson, W. (1985, May 13). Steroids: A Problem of Huge Dimensions. Sports Illustrated , pp. 38-61.

Johnston, L. D., O'Malley, P. M., Bachman, J. G., \& Schulenberg, J. E. (2011). Monitoring the Future National Survey Results on Drug Use, 1975-2010: Volume I, Secondary School Students. Ann Arbor: Institute for Social Research, University of Michigan, Ann Arbor.

Keteyian, A. (1987, January 5). A Former Husker Fesses Up. Sports Illustrated , p. 24. Longshore, D. (1998). Self-Control and Criminal Opportunity: A Prospective Test of the General Theory of Crime. Social Problems , 45 (1), 102-113.

Longshore, D., Chang, E., Hsieh, S.-c., \& Messina, N. (2004). Self-Control and Social Bonds: A Combined Control Perspective on Deviance. Crime \& Delinquency, $50(4), 542-564$.

Luke, J. L., Farb, A., Virmani, R., \& Sample, R. H. (1990). Sudden Cardiac Death During Exercise in a Weight Lifter Using Anabolic Androgenic Steroids: Pathological and Toxicology Findings. Journal of Forensic Sciences, 35, 1441-1447. 
Lundholm, L., Kall, K., Wallin, S., \& Thiblin, I. (2010). Use of anabolic androgenic steroids in substance abusers arrested for crime. Drug and Alcohol Dependence , 222-226.

McNutt, R. A., Ferenchick, G. S., Kirlin, P. C., \& Hamlin, N. J. (1988). Acute Myocardial Infarction in a 22-Year-Old World Class Weight Lifter Using Anabolic Steroids. American Journal of Cardiology , 62, 164.

Miller, J. (2009). Drug Issues in Sport: Steroid Performance-Enhancement. In J. W. Lee, \& J. C. Lee, Sport and Criminal Behavior (pp. 19-41). Durham: Carolina Academic Press.

Miller, K. E., Barnes, G. M., Sabo, D. F., Melnick, M. J., \& Farrell, M. P. (2002). AnabloicAndrogenic Steroid Use and Other Adolescent Problem Behaviors: Rethinking the Male Athlete Assumption. Sociological Perspectives , 467-489.

Mochizuki, R. M., \& Richter, K. J. (1988). Cardiomyopathy and Cerebrovascular Accident Associated with Anabolic-Androgenic Steroid Use. The Physician and Sportsmedicine , 16, 109-114.

Morris, G. D., Wood, P. B., \& Dunaway, R. G. (2006). Self-Control, Native Tradionalism and Native American Substance Use: Testing the Cultural Invariance of a General Theory of Crime. Crime and Delinquency .

National Institute on Drug Abuse. (2009). Steroids (Anabolic-Androgenic). US Department of Health and Human Services.

Neff, J. L., \& Waite, D. E. (2007). Male Versus Female Substance Abuse Patterns Among Incarcerated Juvenile Offenders: Comparing Strain and Social Learning Variables. Justice Quarterly , 24 (1), 106-132. 
Nieminen, M. S., Raemoe, M. P., Viitasalo, M., Heikkilae, M., Karjalaninen, J., Maentysaari, M., et al. (1996). Serious Cardiovascular Side Effects of Larger Doses of Anabolic Steroids in Weight Lifters. European Heart Journal, 17, 1576-1583.

Nightengale, B. (1995, July 15). Many Fear Performance-Enhancing Drug is Becoming Prevalent and Believe Something Must Be Done. Los Angeles Times

Noonan, D. (1997, December 14). Really Big Football Players. New York Times Magazine , pp. 64-69.

Overly, W. L., Dankoff, J. A., Wang, B. K., \& Singh, U. D. (1984). Androgens and Hepatocelluar Carcinoma in an Athlete. Annals of Internal Medicine , 158-159.

Parrott, A. C., Choi, P. Y., \& Davies, M. (1994). Anabolic Steroid Use by Amateur Athletes: Effects Upon Psychological Mood States. J Sports Med Phys Fitness, $34,292-349$.

Pedersen, W., Wichstrom, L., \& Blekesaune, M. (2001). Violent Behaviors, Violent Victimization, and Doping Agents. Journal of Interpersonal Violence , 808-832.

Piquero, A. R., \& Bouffard, J. (2007). Something old, something new: A preliminary investigation of Hirschi's redefined self-control. Justice Quarterly, 24, 1-27.

Pope, H. G., \& Katz, D. L. (1998). Affective and Psychotic Symptoms Associated with Anabolic Steroid Use. Am J Psychiatry, 145, 487-490.

Pope, H. G., \& Katz, D. L. (1987). Bodybuilder's Psychosis. Lancet, 863.

Pope, H. G., \& Katz, D. L. (1990). Homicide and Near-Homicide by Anabolic Steroid Users. J Clin Psychiatry, 51, 28-31. 
Pope, H. G., \& Katz, D. L. (1994). Psychiatric and Medical Effects of Anabolic Steroid Use: A Controlled Study of 160 Athletes. Archieves of General Psychiatry, 375382.

Pope, H. G., Kouri, E. M., \& Hudson, J. I. (2000). Effects of Supraphysiologic Doses of Testerone on Mood and Aggression in Normal Men: A Randomized Controlled Trial. Archieves of General Psychiatry, 133-140.

Porcerelli, J. H., \& Sandler, B. A. (1995). Narcissism and Empathy in Steroid Users. Am J Psychiatry, 152, 1672-1674.

Potteiger, J. A., \& Stilger, V. G. (1994). Anabolic Steroid Use in the Adolescent Athlete. Journal of Athletic Training , 60-64.

Pratt, T. C., \& Cullen, F. T. (2000). The Empirical Status of Gottfredson and Hirschi's General Theory of Crime: A Meta-Analysis. Criminology , 38 (3), 931-964.

Pratt, T. C., Cullen, F. T., Sellers, C. S., Winfree Jr., L. T., Madensen, T. D., Daigle, L. E., et al. (2010). The Empirical Status of Social Learning Theory: A Meta-Analysis. Justice Quarterly, 27 (6), 765-802.

Radakovich, J., Broderick, P., \& Pickell, G. (1993). Rate of Anabolic Androgenic Steroid Use Among Students in Junior High School. Journal of the American Board of Family Practice, 6, 341-345.

Ragan, D. T., \& Beaver, K. M. (2010). Chronic Offenders: A Life-Course Analysis of Marijuana Users. Youth and Society , 174-198.

Scott, M. J., \& Scott Jr., M. j. (1989). HIV Infection Associated with Injections of Anabolic Steroids. Journal of American Medical Association , 262, 207-298. 
Sklarek, H. M., Mantovani, R. P., Erens, E., Heisler, D., Niederman, M. S., \& Fein, A. M. (1984). AIDS in a Bodybuilder Using Anabolic Steroids. New England Journal of Medicine, 311, 1701.

Sorenson, A. M., \& Brownfield, D. (1995). Adolescent Drug Use and A General Theory of Crime: An Analysis of a Theoretical Integration. Candian Journal of Criminology, 19-37.

Steele, J. L., Peralta, R. L., \& Elman, C. (2011). The Co-Ingestion of Nonmedical Prescription Drugs and Alcohol: A Partial Test of Social Learning Theory. Journal of Drug Issues, 41 (4), 561-585.

Stilger, V., \& Yesalis, C. (1999). Anabolic-Androgenic Steroid Use Among High School Football Players. Journal of Community Health, 24 (2), 131-145.

Sun , I. Y., \& Longazel, J. G. (2008). College Students' Alcohol-Related Problems: A Test of Competing Theories. Journal of Criminal Justice, 554-562.

Sutherland, E. H. (1947). Principles of Criminology (Vol. 4). Philadelphia: Lippincott. Tanner, S., Miller, D., \& Alongi, C. (1995). Anabolic Steroid Use by Adolescents: Prevalance, Motives, and Knowledge of risks. Clinical Journal of Sports Medicine , 5, 108-115.

Terney, R., \& McLain, L. G. (1990). The Use of Anabolic Steroids in High School Students. Am J Dis Child , 144, 99-103.

Thiblin, I., Runeson, B., \& Rajs, J. (1999). Anabolic Androgenic Steroids and Suicide. Annals of Clinical Psychiatry, 11 (4), 223-231.

Todd, T. (1987). Anabolic Steroids: The Gremlins of Sport. Journal of Sport History, $14,87-107$ 
Trenton, A. J., \& Currier, G. W. (2005). Behavioural Manifestations of Anabolic Steroid Use. CNS Drugs , 571-595.

Urdang, L. (2009). The Bantam Medical Dictionary (Vol. 5). New York City: Random House Digital.

Wichstrom, L., \& Pedersen, W. (2001). Use of Anabolic-Androgenic Steroids in Adolescence: Winning, Looking Good ro Being Bad? Journal of Studies on Alcohol , 5-13.

Yesalis, C. E., Streit, A. L., Vicary, J. R., Friedl, K. E., Brannon, D., \& Buckley, W. (1989). Anabolic steroid use: Indications of habituation among adolescents. Journal of Drug

Education, 19, 103-116.

Yesalis, C. E., Barsukiewicz, C. K., Kopstein, A. N., \& Bahrke, M. S. (1997). Trends in Anabolic-Androgenic Steroid Use Among Adolescents. Archieves of Pediatrics \& Adolescent Medicine, 1197-1206.

Yesalis, C. E., Courson, S. P., \& Wright, J. E. (2000). History of Anabolic Steroid Use in Sport and Exercise. In C. E. Yesalis, Anabolic Steroids in Sport and Exercise (2nd Edition ed., pp. 51-66). Champaign, IL: Human Kinetics.

Yesalis, C. E., Kennedy, N. J., Kopstein, A. N., \& Bahrke, M. S. (1993). AnabolicAndrogenic Steroid Use in the United States. The Journal of the American Medical Association , 1217-1221.

Youth Risk Behavior Survey. (2009). 2009 National Youth Risk Behavior Survey. Youth Risk Behavior Survey. 


\section{CURRICULM VITAE}

Name: $\quad$ Anthony Vito

Address: Justice Administration

2311 S. Third St.

University of Louisville

Louisville, KY 40292

DOB: $\quad$ March 14, 1987

Education

\& Training: B.S., Justice Administration

University of Louisville

2005-10

Awards: $\quad$ University of Louisville

Dean's List Fall 2008 and Spring 2009

PROFESSIONAL SOCIETIES: Academy of Criminal Justice Sciences

PUBLICATIONS:

Vito, A.G., Higgins, G.E., Vito, G.F., \& Walsh, W.F. (forthcoming). "The Threat of Methamphetamine Use and Production: Evaluation Results from a Kentucky Law Enforcement Program." International Journal of Police Science and Management

Higgins, G.E., Vito, G.F., Grossi, E.L., \& Vito, A.G. (forthcoming). "Searches and Traffic Stops: Racial Profiling and Capriciousness." Journal of Ethnicity in Criminal Justice.

Vito, A.G., and Vito, G.F. (forthcoming). "Lessons for Policing from Moneyball the Views of Police Managers - A Research Note." American Journal of Criminal Justice

NATIONAL MEETING PRESENTATIONS:

Poster Session Presentation: "Meth Lab Locations and Arrest Patterns in Louisville, KY." Annual Conference of the Academy of Criminal Justice Sciences, March 2010. 
Poster Session Presentation: "Lessons for Policing from Moneyball the Views of Police Managers." Annual Conference of the Academy of Criminal Justice Sciences, March 2012. This poster was also presented at The $4^{\text {th }}$ Annual Graduate Research Symposium at the University of Louisville, March 2012. 